\title{
APÊNDICE F.5
}

Memória de cálculo das simulações ambiciosa e conservadora

Definições:

\begin{tabular}{|l|l|}
\hline DOMíNIO & Domínio conforme estrutura do IMUS \\
\hline TEMA & Tema conforme estrutura do IMUS \\
\hline INDICADOR (ID) & Identificação do Indicador \\
\hline
\end{tabular}

Definição: Breve descrição do indicador de acordo com o Guia de Indicadores do IMUS.

Escore: Resultado obtido para o indicador no IMUS 2009, não normalizado.

Normalização: Resultado normalizado em escala de 0 a 1 de acordo com a tabela de normalização indicada no Guia de Indicadores do IMUS.

Estágios: (Tabela contendo os diversos valores em que podem ser avaliado entre 0 e 1 e as ações necessárias para obter tal valor).

\begin{tabular}{|c|l|}
\hline Escore & $\begin{array}{l}\text { Valores de Referência: } \\
\text { Ações necessárias para obter o escore correspondente. }\end{array}$ \\
\hline 1,00 & Estágio 1 \\
\hline 0,75 & Estágio 2 \\
\hline 0,50 & Estágio 3 \\
\hline 0,25 & Estágio 4 \\
\hline 0,00 & Estágio 5 \\
\hline
\end{tabular}

\section{SIMULAČ̃O AMBICIOSA E CONSERVADORA:}

Variação de Estágio: Variação do estágio (tabela 7 do texto) $\times$ Variação de unidades entre cada estágio $=$ Valor a ser variado e sua unidade (quando os estágios são quantitativos a unidade de medida pode ser o próprio escore).

Escore a ser atingido: Escore 2009 + Variação do estágio = Escore da simulação não normalizado.

Valor normalizado: Resultado da simulação normalizado em escala de 0 a 1 de acordo com a tabela de normalização indicada no Guia de Indicadores do IMUS.

Ação consequente: Ações necessárias para alcançar tal escore ou mudar de estágio. Saem da coluna valores de referências da tabela de estágios. 


\begin{tabular}{|l|l|}
\hline DOMÍNIO & Acessibilidade \\
\hline TEMA & Acessibilidade aos sistemas de transportes \\
\hline INDICADOR 1.1.1 & Acessibilidade ao transporte público \\
\hline
\end{tabular}

Definição: Porcentagem da população urbana residente na área de cobertura de um ponto de acesso aos serviços de transporte público, considerando todos os modos disponíveis.

Escore: $63,7 \%$

Valor: 0,60

Estágios:

\begin{tabular}{|c|l|}
\hline Escore & $\begin{array}{l}\text { Valores de Referência } \\
\text { Porcentagem da população urbana residente na área de cobertura } \\
\text { de pontos de acesso ao transporte público }\end{array}$ \\
\hline 1,00 & $100 \%$ \\
\hline 0,75 & $77,5 \%$ \\
\hline 0,50 & $55 \%$ \\
\hline 0,25 & $32,5 \%$ \\
\hline 0,00 & Até $10 \%$ \\
\hline
\end{tabular}

SIMULACÃO AMBICIOSA:

Variação de Estágio: $1,5 \times 22,5 \%=33,75 \%$

Escore a ser atingido: $63,7 \%+33,75=97,45 \%$

Valor normalizado: 0,97

Ação consequente: Aumentar área de abrangência do TC, para atender 175.887 habitantes ${ }^{1}$.

\section{SIMULAC̄̃̃O CONSERVADORA:}

Variação de Estágio: $0,5 \times 22,5 \%=11,25 \%$

Escore a ser atingido: $63,7 \%+11,25=74,95 \%$

Valor normalizado: 0,72

Ação consequente: Aumentar área de abrangência do TC, para atender 135.277 habitantes ${ }^{1}$.

\footnotetext{
${ }^{1}$ Baseado na população do Censo 2000: 180.490 habitantes.
} 


\begin{tabular}{|l|l|}
\hline DOMÍNIO & Acessibilidade \\
\hline TEMA & Acessibilidade aos sistemas de transportes \\
\hline INDICADOR 1.1.2 & $\begin{array}{l}\text { Transporte público para pessoas com necessidades } \\
\text { especiais }\end{array}$ \\
\hline
\end{tabular}

Definição: Porcentagem dos veículos da frota municipal de transporte público por ônibus adaptada para pessoas com necessidades especiais e restrições de mobilidade.

Escore: Há serviços especiais para transporte de pessoas com necessidades especiais.

Normalização: 1,00

\section{Estágios:}

\begin{tabular}{|c|l|}
\hline Escore & $\begin{array}{l}\text { Valores de Referência } \\
\text { Porcentagem da frota municipal de ônibus urbano adaptada para } \\
\text { pessoas com necessidades especiais ou restrições de mobilidade }\end{array}$ \\
\hline 1,00 & $\begin{array}{l}\text { Mais de } 75 \% \text { (ou há serviços especiais para transporte de pessoas } \\
\text { com necessidades especiais) }\end{array}$ \\
\hline 0,75 & $75 \%$ \\
\hline 0,50 & $50 \%$ \\
\hline 0,25 & $25 \%$ \\
\hline 0,00 & $\begin{array}{l}0 \text { (ou não há serviços especiais para transporte de pessoas com } \\
\text { necessidades especiais) }\end{array}$ \\
\hline
\end{tabular}

\section{SIMULACÃO AMBICIOSA:}

Variação de Estágio: 2

Escore a ser atingido: Já está no máximo.

Valor normalizado: 1,00

Ação consequente: Manter o serviço de transportes às pessoas com necessidades especiais.

\section{SIMULAČ̃̃O CONSERVADORA:}

\section{Variação de Estágio: 1}

Escore a ser atingido: Já está no máximo

Valor normalizado: 1,00

Ação consequente: Manter o serviço de transportes às pessoas com necessidades especiais. 


\begin{tabular}{|l|l|}
\hline DOMÍNIO & Acessibilidade \\
\hline TEMA & Acessibilidade aos sistemas de transportes \\
\hline INDICADOR 1.1.3 & Despesas com Transportes \\
\hline
\end{tabular}

Definição: Porcentagem da renda mensal pessoal (ou do domicilio) gasta com transporte público.

Escore: $16,41 \%$

Normalização: 0,43

Estágios:

\begin{tabular}{|c|l|}
\hline Escore & $\begin{array}{l}\text { Valores de Referência } \\
\text { Porcentagem da renda mensal pessoal (ou domiciliar) relativa a } \\
\text { despesas com transporte público }\end{array}$ \\
\hline 1,00 & Até $5 \%$ \\
\hline 0,75 & $10 \%$ \\
\hline 0,50 & $15 \%$ \\
\hline 0,25 & $20 \%$ \\
\hline 0,00 & Mais de $20 \%$ \\
\hline
\end{tabular}

\section{SIMULACÃO AMBICIOSA:}

Variação de Estágio: $1,5 \times-5 \%=-7,5 \%$

Escore a ser atingido: $16,41 \%-7,5 \%=8,91 \%$

Valor normalizado: 0,80

Ação consequente: Aumentar a renda média para $\mathrm{R} \$ 954,07$ ou diminuir o custo da passagem para $\mathrm{R} \$ 1,20^{2}$.

\section{SIMULAC̄̃̃O CONSERVADORA:}

Variação de Estágio: $0,5 \times-5 \%=2,5 \%$

Escore a ser atingido: $63,7 \%-2,5 \%=13,91 \%$

Valor normalizado: 0,55

Ação consequente: Aumentar a renda média para $\mathrm{R} \$ 611,13$ ou diminuir o custo da passagem para $\mathrm{R} \$ 1,86^{2}$.

\footnotetext{
${ }^{2}$ Baseado no custo da passagem de $R \$ 2,30$, renda média de $R \$ 495,42$ da pesquisa OD, 1,68 viagens diárias e 22 dias úteis mensais.
} 


\begin{tabular}{|l|l|}
\hline DOMÍNIO & Acessibilidade \\
\hline TEMA & Acessibilidade Universal \\
\hline INDICADOR 1.2.1 & $\begin{array}{l}\text { Travessias adaptadas para pessoas com necessidades } \\
\text { especiais }\end{array}$ \\
\hline
\end{tabular}

Definição: Porcentagem das travessias de pedestres da rede viária principal adaptadas e atendendo aos padrões de conforto e segurança para pessoas com necessidades especiais e restrições de mobilidade.

Escore: 8\%

Normalização: 0,08

Estágios:

\begin{tabular}{|c|l|}
\hline Escore & $\begin{array}{l}\text { Valores de Referência } \\
\text { Porcentagem das travessias da rede viária principal adaptada a } \\
\text { pessoas com necessidades especiais e restrições de mobilidade }\end{array}$ \\
\hline 1,00 & $100 \%$ \\
\hline 0,75 & $75 \%$ \\
\hline 0,50 & $50 \%$ \\
\hline 0,25 & $25 \%$ \\
\hline 0,00 & 0 \\
\hline
\end{tabular}

\section{SIMULAC̄̃̃O AMBICIOSA:}

Variação de Estágio: $1,5 \times 25 \%=37,5 \%$

Escore a ser atingido: $8 \%+37,5=45,5 \%$

Valor normalizado: 0,46

Ação consequente: Adaptar mais 793 travessias para pessoas com necessidades especiais ${ }^{3}$.

\section{SIMULAC̄̃̃O CONSERVADORA:}

Variação de Estágio: $0,25 \times 25 \%=6,25 \%$

Escore a ser atingido: $8 \%+6,25=14,25 \%$

Valor normalizado: 0,14

Ação consequente: Adaptar mais 136 travessias para pessoas com necessidades especiais ${ }^{3}$.

\footnotetext{
${ }^{3}$ Baseado em no valor total de 2099 travessias contabilizadas em 2007.
} 


\begin{tabular}{|l|l|}
\hline DOMÍNIO & Acessibilidade \\
\hline TEMA & Acessibilidade universal \\
\hline INDICADOR 1.2.2 & Acessibilidade aos espaços abertos \\
\hline
\end{tabular}

Definição: Porcentagem da população urbana residente próxima a áreas abertas (áreas verdes ou de lazer), considerando os seguintes parâmetros:

- Até 500 metros de praças, playgrounds e outras áreas de recreação de pequeno e médio porte;

- Até 1000 metros de parques urbanos.

Escore: 93,3\%

Normalização: 0,93

Estágios:

\begin{tabular}{|c|l|}
\hline Escore & $\begin{array}{l}\text { Valores de Referência } \\
\text { Porcentagem da população urbana que reside na área de } \\
\text { influência de espaços verdes e de recreação }\end{array}$ \\
\hline 1,00 & $100 \%$ \\
\hline 0,75 & $75 \%$ \\
\hline 0,50 & $50 \%$ \\
\hline 0,25 & $25 \%$ \\
\hline 0,00 & 0 \\
\hline
\end{tabular}

\section{SIMULACÃO AMBICIOSA:}

Variação de Estágio: $1,5 \times 25 \%=37,5 \%$

Escore a ser atingido: $93,3 \%+37,5=100 \%$ (valor extrapola o máximo)

Valor normalizado: 1,00

Ação consequente: Prover espaços verdes para 12.152 habitantes, nas áreas não contidas a um raio de 1000 metros de parques urbanos ou 500 metros de praças ${ }^{4}$.

\section{SIMULACÃO CONSERVADORA:}

Variação de Estágio: $0,5 \times 25 \%=12,5 \%$

Escore a ser atingido: $93,3 \%+12,5=100 \%$ (valor extrapola o máximo)

Valor normalizado: 1,00

\footnotetext{
${ }^{4}$ População do Censo 2000 e mapas do ano de 2008.
} 
Ação consequente: Prover espaços verdes para 12.152 habitantes, nas áreas não contidas a um raio de 1000 metros de parques urbanos ou 500 metros de praças $^{4}$. 


\begin{tabular}{|l|l|}
\hline DOMÍNIO & Acessibilidade \\
\hline TEMA & Acessibilidade universal \\
\hline INDICADOR 1.2.3 & $\begin{array}{l}\text { Vagas de estacionamento para pessoas com } \\
\text { necessidades especiais }\end{array}$ \\
\hline
\end{tabular}

Definição: Porcentagem de vagas em estacionamentos públicos para pessoas com necessidades especiais.

Escore: 1,00

Normalização: 1,00

Estágios:

\begin{tabular}{|c|l|}
\hline Escore & Valores de Referência \\
\hline 1,00 & $\begin{array}{l}\text { Há disponibilidade de vagas para pessoas com necessidades } \\
\text { especiais em número superior aos valores estabelecidos por lei } \\
\text { específica (ou indicados na NBR 9050) e estas se encontram } \\
\text { devidamente sinalizadas e dimensionadas }\end{array}$ \\
\hline 0,80 & $\begin{array}{l}\text { Há disponibilidade de vagas para pessoas com necessidades } \\
\text { especiais em número superior aos valores estabelecidos por lei } \\
\text { específica (ou indicados na NBR 9050), porém as vagas estão mal } \\
\text { sinalizadas ou não apresentam as dimensões adequadas }\end{array}$ \\
\hline 0,60 & $\begin{array}{l}\text { Há disponibilidade de vagas para pessoas com necessidades } \\
\text { especiais em número igual aos valores estabelecidos por lei } \\
\text { específica (ou indicados na NBR 9050) e estas se encontram } \\
\text { devidamente sinalizadas e dimensionadas }\end{array}$ \\
\hline 0,40 & $\begin{array}{l}\text { Há disponibilidade de vagas para pessoas com necessidades } \\
\text { especiais em número igual aos valores estabelecidos por lei } \\
\text { específica (ou indicados na NBR 9050), porém as vagas estão mal } \\
\text { sinalizadas ou não apresentam as dimensões adequadas }\end{array}$ \\
\hline 0,00 & $\begin{array}{l}\text { Há disponibilidade de vagas para pessoas com necessidades } \\
\text { especiais em número inferior aos valores estabelecidos por lei } \\
\text { específica (ou indicados na NBR 9050) }\end{array}$ \\
$\begin{array}{l}\text { Não há disponibilidade de vagas para pessoas com necessidades } \\
\text { especiais em estacionamentos públicos }\end{array}$ \\
\hline
\end{tabular}

\section{SIMULACÃO AMBICIOSA:}

Variação de Estágio: 2

Escore a ser atingido: Já está no máximo.

Valor normalizado: 1,00

Ação consequente: Manter o número de vagas necessário conforme as normas vigentes. 


\section{SIMULACÃO CONSERVADORA:}

Variação de Estágio: 1

Escore a ser atingido: Já está no máximo

Valor normalizado: 1,00

Ação consequente: Manter o número de vagas necessário conforme as normas vigentes. 


\begin{tabular}{|l|l|}
\hline DOMÍNIO & Acessibilidade \\
\hline TEMA & Acessibilidade universal \\
\hline INDICADOR 1.2.4 & Acessibilidade a edifícios públicos \\
\hline
\end{tabular}

Definição: Porcentagem de edifícios públicos adaptados para acesso e utilização de pessoas com necessidades especiais ou restrições de mobilidade.

Observação: $A$ insuficiência de dados impossibilitou a execução do cálculo deste indicador. Nos cenários também não foram calculados para evitar a redistribuição dos pesos entre os indicadores.

\section{Escore: -}

Normalização: -

Estágios:

\begin{tabular}{|c|l|}
\hline Escore & $\begin{array}{l}\text { Valores de Referência } \\
\text { Porcentagem de edifícios públicos adaptados para acesso de } \\
\text { pessoas com necessidades especiais ou restrições de mobilidade }\end{array}$ \\
\hline 1,00 & $100 \%$ \\
\hline 0,75 & $75 \%$ \\
\hline 0,50 & $50 \%$ \\
\hline 0,25 & $25 \%$ \\
\hline 0,00 & 0 \\
\hline
\end{tabular}

SIMULACÃO AMBICIOSA:

Variação de Estágio: 1,5

Escore a ser atingido: -

Valor normalizado: -

Ação consequente: - .

\section{SIMULACÃO CONSERVADORA:}

Variação de Estágio: 0,5

Escore a ser atingido: -

Valor normalizado: -

Ação consequente: - 


\begin{tabular}{|l|l|}
\hline DOMÍNIO & Acessibilidade \\
\hline TEMA & Acessibilidade universal \\
\hline INDICADOR 1.2.5 & Acessibilidade aos serviços essenciais \\
\hline
\end{tabular}

Definição: Porcentagem da população urbana residente até 500 metros de distância de serviços essenciais, entendidos aqui como equipamentos de saúde de atendimento primário e equipamentos de educação infantil.

Escore: $77,2 \%$

Normalização: 0,75

Estágios:

\begin{tabular}{|l|l|}
\hline Escore & $\begin{array}{l}\text { Valores de Referência } \\
\text { Porcentagem da população urbana residente até } 500 \text { metros de } \\
\text { um equipamento de saúde e/ou educação }\end{array}$ \\
\hline 1,00 & $100 \%$ \\
\hline 0,75 & $77,5 \%$ \\
\hline 0,50 & $55 \%$ \\
\hline 0,25 & $32,5 \%$ \\
\hline 0,00 & Até $10 \%$ \\
\hline
\end{tabular}

SIMULACÃO AMBICIOSA:

Variação de Estágio: $1,25 \times 22,5 \%=28,13 \%$

Escore a ser atingido: $77,2 \%+28,13 \%=100 \%$ (valor extrapola o máximo)

Valor normalizado: 1,00

Ação consequente: Construir equipamentos de serviços essenciais para 41.224 pessoas, priorizando áreas com distância maior que um raio de 500 metros dos equipamentos existentes no ano de $2007^{5}$.

\section{SIMULAC̄̃̃O CONSERVADORA:}

Variação de Estágio: $0,1 \times 22,5 \%=2,25 \%$

Escore a ser atingido: $77,2 \%+2,25 \%=79,45 \%$

Valor normalizado: 0,77

Ação consequente: Construir equipamentos de serviços essenciais para 4.133 pessoas, priorizando áreas com distância maior que um raio de 500 metros dos equipamentos existentes no ano de $2007^{5}$.

${ }^{5}$ Baseado na população do censo 2000 e na base georeferenciada de 2007 (IMUS) 


\begin{tabular}{|l|l|}
\hline DOMÍNIO & Acessibilidade \\
\hline TEMA & Barreiras físicas \\
\hline INDICADOR 1.3.1 & Fragmentação urbana \\
\hline
\end{tabular}

Definição: Proporção de terra urbanizada contínua do total da área urbanizada do município, ou seja, não cortada por infraestrutura de transporte principal como vias de trânsito rápido (rodovias, vias expressas e vias arteriais), corredores de transporte coletivo, vias para transporte ferroviário ou metroviário de superfície, terminais de transporte de grande porte, ou qualquer outra barreira física, natural ou construída, que acarrete em descontinuidade do tecido urbano.

Escore: 23 blocos

Normalização: 0,00

Estágios:

\begin{tabular}{|l|l|}
\hline Escore & $\begin{array}{l}\text { Valores de Referência } \\
\text { Número de subdivisões (parcelas) da área urbanizada do } \\
\text { município em função da infraestrutura de transportes }\end{array}$ \\
\hline 1,00 & $0(100 \%$ da área urbanizada é contínua) \\
\hline 0,75 & 5 \\
\hline 0,50 & 10 \\
\hline 0,25 & 15 \\
\hline 0,00 & 20 ou mais \\
\hline
\end{tabular}

\section{SIMULAČ̃̃ AMBICIOSA:}

Variação de Estágio: $0,5 \times-5 \%=-2,5 \%$

Escore a ser atingido: $23-2,5$ (aproximou-se para 3 ) $=20$

Valor normalizado: 0,00

Ação consequente: Criar continuidade para 3 dos 23 blocos existentes na área urbana do município ${ }^{6}$.

\section{SIMULAC̄̃̃O CONSERVADORA:}

Variação de Estágio: Não há

Escore a ser atingido: -

Valor normalizado: 0,00

${ }^{6}$ Conforme base georefenciada de 2007. 


\begin{tabular}{|l|l|}
\hline DOMÍNIO & Acessibilidade \\
\hline TEMA & Legislação para pessoas com necessidades especiais \\
\hline INDICADOR 1.4.1 & Ações para acessibilidade universal \\
\hline
\end{tabular}

Definição: Existência e tipos de ações, medidas, programas ou instrumentos, incluindo campanhas, projetos, legislação e normas técnicas destinadas à promoção de acessibilidade universal.

Escore: O município dispõe de legislação específica, normas técnicas, recomendações e ações ou programas de iniciativa pública para acessibilidade universal.

Normalização: 0,75

\section{Estágios:}

\begin{tabular}{|c|l|}
\hline Escore & Valores de Referência \\
\hline 1,00 & $\begin{array}{l}\text { O município dispõe de legislação específica, normas técnicas, } \\
\text { recomendações, programas de iniciativa pública e campanhas de } \\
\text { educação e sensibilização para acessibilidade universal }\end{array}$ \\
\hline 0,75 & $\begin{array}{l}\text { O município dispõe de legislação específica, normas técnicas, } \\
\text { recomendações e ações ou programas de iniciativa pública para } \\
\text { acessibilidade universal }\end{array}$ \\
\hline 0,50 & $\begin{array}{l}\text { O município dispõe de legislação específica, normas técnicas e } \\
\text { recomendações para acessibilidade universal }\end{array}$ \\
\hline 0,25 & $\begin{array}{l}\text { O município dispõe de legislação específica sobre acessibilidade } \\
\text { universal }\end{array}$ \\
\hline 0,00 & $\begin{array}{l}\text { O município não dispõe de qualquer ação ou instrumento para } \\
\text { acessibilidade universal }\end{array}$ \\
\hline
\end{tabular}

\section{SIMULACÃO AMBICIOSA:}

Variação de Estágio: $2 \times 0,25=0,5$

Escore a ser atingido: $0,75+0,5=1,00$ (Valor extrapola o máximo)

Valor normalizado: 1,00

Ação consequente: Promover campanhas de educação e sensibilização para acessibilidade universal.

\section{SIMULACÃO CONSERVADORA:}

Variação de Estágio: $1 \times 0,25=0,25$

Escore a ser atingido: $0,75+0,25=1,00$

Valor normalizado: 1,00 
Ação consequente: Promover campanhas de educação e sensibilização para acessibilidade universal. 


\begin{tabular}{|l|l|}
\hline DOMÍNIO & Aspectos Ambientais \\
\hline TEMA & Controle dos impactos no meio ambiente \\
\hline INDICADOR 2.1.1 & Emissões de CO \\
\hline
\end{tabular}

Definição: Emissões anuais de monóxido de carbono (CO) por veículos automotores.

Escore: 113,13\%

Normalização: 0,00

Estágios:

\begin{tabular}{|c|l|}
\hline Escore & $\begin{array}{l}\text { Valores de Referência } \\
\text { Parâmetro de controle: Quilometragem anual percorrida pela frota } \\
\text { municipal de veículos leves em área urbana vezes o limite para } \\
\text { níveis de emissão de CO para veículos leves novos (2,0 g/km) } \\
\text { quilometragem anual percorrida pela frota municipal de veículos } \\
\text { ciclomotores em área urbana vezes o limite para níveis de emissão } \\
\text { de CO para ciclomotores novos (5,5 g/km, respectivamente) }\end{array}$ \\
\hline 1,00 & $\begin{array}{l}\text { A emissão de CO anual por veículos automotores é igual ou } \\
\text { inferior ao parâmetro de controle }\end{array}$ \\
\hline 0,75 & $\begin{array}{l}\text { A emissão de CO anual por veículos automotores é 25\% maior } \\
\text { que o parâmetro de controle }\end{array}$ \\
\hline 0,50 & $\begin{array}{l}\text { A emissão de CO anual por veículos automotores é 50\% maior } \\
\text { que o parâmetro de controle }\end{array}$ \\
\hline 0,25 & $\begin{array}{l}\text { A emissão de CO anual por veículos automotores é 75\% maior } \\
\text { que o parâmetro de controle }\end{array}$ \\
\hline 0,00 & $\begin{array}{l}\text { A emissão de CO anual por veículos automotores é 100\% maior } \\
\text { que parâmetro de controle }\end{array}$ \\
\hline
\end{tabular}

SIMULAC̣ÃO AMBICIOSA:

Variação de Estágio: $1 \times-25 \%=-25 \%$

Escore a ser atingido: $113,13 \%-25 \%=88,13 \%$

Valor normalizado: 0,12

Ação consequente: Diminuir a emissão anual para 14,9 Kg/ano de CO por veículo automotor ${ }^{7}$.

\footnotetext{
${ }^{7}$ Adotando-se os dados de 2008, cuja emissão era de 16,2 Kg de CO/ano/habitante.
} 


\section{SIMULACÃO CONSERVADORA:}

Variação de Estágio: $0,1 \times-25 \%=-2,5 \%$

Escore a ser atingido: $113,13 \%-2,5=110,63 \%$

Valor normalizado: 0,00

Ação consequente: Diminuir a emissão anual para 16,6 Kg/ano de CO por veículo automotor?. 


\begin{tabular}{|l|l|}
\hline DOMÍNIO & Aspectos Ambientais \\
\hline TEMA & Controle dos impactos no meio ambiente \\
\hline INDICADOR 2.1.2 & Emissões de $\mathrm{CO}_{2}$ \\
\hline
\end{tabular}

Definição: Emissões anuais de dióxido de carbono $\left(\mathrm{CO}_{2}\right)$ por veículos automotores.

Escore: $21,24 \%$

Normalização: 0,79

Estágios:

\begin{tabular}{|c|l|}
\hline Escore & Valores de Referência \\
\hline 1,00 & $\begin{array}{l}\text { A emissão de } \mathrm{CO}_{2} \text { anual por veículos automotores é igual ou } \\
\text { inferior ao parâmetro de controle }\end{array}$ \\
\hline 0,75 & $\begin{array}{l}\text { A emissão de } \mathrm{CO}_{2} \text { anual por veículos automotores é } 25 \% \text { maior } \\
\text { que o parâmetro de controle }\end{array}$ \\
\hline 0,50 & $\begin{array}{l}\text { A emissão de } \mathrm{CO}_{2} \text { anual por veículos automotores é } 50 \% \text { maior } \\
\text { que o parâmetro de controle }\end{array}$ \\
\hline 0,25 & $\begin{array}{l}\text { A emissão de } \mathrm{CO}_{2} \text { anual por veículos automotores é } 75 \% \text { maior } \\
\text { que o parâmetro de controle }\end{array}$ \\
\hline 0,00 & $\begin{array}{l}\text { A emissão de } \mathrm{CO}_{2} \text { anual por veículos automotores é } 100 \% \text { maior } \\
\text { que parâmetro de controle }\end{array}$ \\
\hline
\end{tabular}

\section{SIMULACÃO AMBICIOSA:}

Variação de Estágio: $1 \times-25 \%=-25 \%$

Escore a ser atingido: $21,24 \%-25 \%=0 \%$ (excede o mínimo)

Valor normalizado: 1,00

Ação consequente: Diminuir a emissão anual para 168,78 Kg/ano de CO2 por veículo automotor ${ }^{8}$.

\section{SIMULACÃO CONSERVADORA:}

Variação de Estágio: $0,1 \times-25 \%=-2,5 \%$

Escore a ser atingido: $21,24 \%-2,5 \%=18,74 \%$

Valor normalizado: 0,81

Ação consequente: Diminuir a emissão anual para $200,40 \mathrm{Kg} /$ ano de $\mathrm{CO}_{2}$ por veículo automotor ${ }^{8}$.

${ }^{8}$ Adotando os mesmos dados de 2009, cuja emissão era de 204,62 Kg de CO$/$ /ano/veículo. 


\begin{tabular}{|l|l|}
\hline DOMÍNIO & Aspectos Ambientais \\
\hline TEMA & Controle dos impactos no meio ambiente \\
\hline INDICADOR 2.1.3 & População exposta ao ruído de tráfego \\
\hline
\end{tabular}

Definição: Porcentagem da população urbana exposta a ruído superior a 65 $\mathrm{dB}(\mathrm{A})$ ocasionado por sistemas de transporte.

Escore: 20,00

Normalização: 0,80

Estágios:

\begin{tabular}{|l|l|}
\hline Escore & $\begin{array}{l}\text { Valores de Referência } \\
\text { Porcentagem da população urbana (ou da área em estudo) } \\
\text { exposta a ruído de tráfego superior a } 65 \mathrm{~dB}(\mathrm{~A})\end{array}$ \\
\hline 1,00 & 0 \\
\hline 0,75 & $25 \%$ \\
\hline 0,50 & $50 \%$ \\
\hline 0,25 & $75 \%$ \\
\hline 0,00 & $100 \%$ \\
\hline
\end{tabular}

\section{SIMULACÃO AMBICIOSA:}

Variação de Estágio: $1 \times-25 \%=-25 \%$

Escore a ser atingido: $20,00 \%-25 \%=0 \%$ (excede o valor mínimo)

Valor normalizado: 1,00

Ação consequente: Não ter população exposta a ruído de tráfego maior que $65 \mathrm{dBA}$ em nenhum ponto do município.

\section{SIMULAC̄̃̃O CONSERVADORA:}

Variação de Estágio: $0,1 \times-25 \%=-2,5 \%$

Escore a ser atingido: $20,00 \%-2,5 \%=17,50 \%$

Valor normalizado: 0,83

Ação consequente: Diminuir 5.260 habitantes de áreas expostas a ruídos maiores que $65 \mathrm{dBA}$ ou reduzir as áreas expostas a este nível de ruídos. 


\begin{tabular}{|l|l|}
\hline DOMÍNIO & Aspectos Ambientais \\
\hline TEMA & Controle dos impactos no meio ambiente \\
\hline INDICADOR 2.1.4 & Estudos de impacto ambiental \\
\hline
\end{tabular}

Definição: Exigência por parte do município de estudos de impacto ambiental, impactos urbanos e de vizinhança para projetos de transportes e mobilidade, incluindo: projetos de infraestrutura viária, terminais de transporte, corredores de transporte público, introdução de novas tecnologias, sistemas de média e alta capacidade, entre outros.

Escore: $O$ município exige estudos de impacto ambiental e estudo de impacto de vizinhança para projetos de transportes e mobilidade urbana e define medidas compensatórias ou mitigadoras.

Normalização: 1,00

Estágios:

\begin{tabular}{|c|l|}
\hline Escore & $\begin{array}{l}\text { Valores de Referência } \\
\text { O município exige: }\end{array}$ \\
\hline 1,00 & $\begin{array}{l}\text { Estudo de impacto ambiental e estudo de impacto de vizinhança } \\
\text { para projetos de transportes e mobilidade urbana, e define } \\
\text { medidas compensatórias ou mitigadoras }\end{array}$ \\
\hline 0,75 & $\begin{array}{l}\text { Estudo de impacto ambiental para projetos de transportes e } \\
\text { mobilidade urbana e define medidas compensatórias ou } \\
\text { mitigadoras }\end{array}$ \\
\hline 0,50 & $\begin{array}{l}\text { Estudo de impacto ambiental e estudo de impacto de vizinhança } \\
\text { para projetos de transportes e mobilidade urbana, mas não define } \\
\text { medidas compensatórias ou mitigadoras }\end{array}$ \\
\hline 0,25 & $\begin{array}{l}\text { Estudo de impacto ambiental para projetos de transportes e } \\
\text { mobilidade urbana, mas não define medidas compensatórias ou } \\
\text { mitigadoras }\end{array}$ \\
\hline 0,00 & $\begin{array}{l}\text { O município não exige qualquer estudo ou medida mitigadora } \\
\text { sobre impactos dos sistemas de transportes e mobilidade urbana }\end{array}$ \\
\hline
\end{tabular}

\section{SIMULACÃO AMBICIOSA:}

Variação de Estágio: 2 × 0,25 = 0,50

Escore a ser atingido: Já está no máximo.

Valor normalizado: 1,00

Ação consequente: Manter as exigências de Estudos de Impacto Ambiental. 


\section{SIMULACẼ̃O CONSERVADORA:}

Variação de Estágio: $1 \times 0,25=0,25$

Escore a ser atingido: Já está no máximo.

Valor normalizado: 1,00

Ação consequente: Manter as exigências de Estudos de Impacto Ambiental. 


\begin{tabular}{|l|l|}
\hline DOMÍNIO & Aspectos Ambientais \\
\hline TEMA & Recursos naturais \\
\hline INDICADOR 2.2.1 & Consumo de combustível \\
\hline
\end{tabular}

Definição: Número de litros de gasolina consumido anualmente por pessoa utilizando veículo motorizado individual na área urbana.

Escore: 234 l/hab

Normalização: 0,91

Estágios:

\begin{tabular}{|c|l|}
\hline Escore & $\begin{array}{l}\text { Valores de Referência } \\
\text { Consumo anual per capita de gasolina em veículo motorizado } \\
\text { individual }\end{array}$ \\
\hline 1,00 & Inferior a $150 \mathrm{I} /$ habitante \\
\hline 0,75 & $300 \mathrm{I} / \mathrm{habitante}$ \\
\hline 0,50 & $450 \mathrm{I} / \mathrm{habitante}$ \\
\hline 0,25 & $600 \mathrm{I} / \mathrm{habitante}$ \\
\hline 0,00 & 750 ou mais $\mathrm{I} / \mathrm{habitante}$ \\
\hline
\end{tabular}

\section{SIMULACÃO AMBICIOSA:}

Variação de Estágio: $1 \times-150 \mid=-150$ I

Escore a ser atingido: $234-150=80 \mathrm{l} / \mathrm{hab} / \mathrm{ano}$

Valor normalizado: 1,00

Ação consequente: Diminuir o consumo anual de combustível para $80 \mathrm{~L} / \mathrm{hab}$.

\section{SIMULACÃO CONSERVADORA:}

Variação de Estágio: $0,1 \times-150=-15$ ।

Escore a ser atingido: $234-15=219 \mathrm{l} / \mathrm{hab} / \mathrm{ano}$

Valor normalizado: 0,89

Ação consequente: Diminuir o consumo anual de combustível para 219 L/hab. 


\begin{tabular}{|l|l|}
\hline DOMÍNIO & Aspectos Ambientais \\
\hline TEMA & Recursos naturais \\
\hline INDICADOR 2.2.2 & Uso de energia limpa e combustíveis alternativos \\
\hline
\end{tabular}

Definição: Porcentagem de veículos da frota municipal de transporte público (ônibus, micro-ônibus, vans) e semipúblico (táxis e serviços especiais) utilizando combustíveis menos poluentes ou fontes de energia alternativa como: gás natural, gás natural líquido, propano, eletricidade, biodiesel, gasolina híbrida ou hidrogênio.

Escore: 17\%

Normalização: 0,17

Estágios:

\begin{tabular}{|c|l|}
\hline Escore & $\begin{array}{l}\text { Valores de Referência } \\
\text { Porcentagem da frota municipal de veículos de transporte público e } \\
\text { semipúblico que utiliza combustíveis "limpos" ou alternativos }\end{array}$ \\
\hline 1,00 & $100 \%$ \\
\hline 0,75 & $75 \%$ \\
\hline 0,50 & $50 \%$ \\
\hline 0,25 & $25 \%$ \\
\hline 0,00 & 0 \\
\hline
\end{tabular}

\section{SIMULAC̄̃̃O AMBICIOSA:}

Variação de Estágio: $1,5 \times 25 \%=37,5 \%$

Escore a ser atingido: $17 \%+37,5 \%=54,5 \%$

Valor normalizado: 0,55

Ação consequente: Aumentar a frota de veículos municipais movidos a combustíveis limpos de 20 para 64 veículos $^{9}$.

\section{SIMULAC̄̃̃O CONSERVADORA:}

Variação de Estágio: $0,25 \times 25 \%=6,25 \%$

Escore a ser atingido: $17 \%+6,25=23,25 \%$

Valor normalizado: 0,23

${ }^{9}$ Baseado no total de 117 veículos levantados. 
Ação consequente: Aumentar a frota de veículos municipais movidos a combustíveis limpos de 20 para 27 veículos $^{9}$. 


\begin{tabular}{|l|l|}
\hline DOMÍNIO & Aspectos Sociais \\
\hline TEMA & Apoio ao cidadão \\
\hline INDICADOR 3.1.1 & Informação disponível ao cidadão \\
\hline
\end{tabular}

Definição: Existência e diversidade de informação sobre mobilidade e transportes urbanos disponibilizados ao cidadão, incluindo: informações sobre os sistemas de transportes em todas as suas modalidades, serviços de auxílio ao usuário, canais de comunicação para reclamações e denúncias, atendimento on-line, informações sobre condições de tráfego e circulação, entre outros.

Escore: Há disponibilidade de informação sobre serviços de transporte público, canais de comunicação para denúncias e reclamações sobre serviços de transporte público e sobre planos e projetos de transporte e mobilidade urbana.

Normalização: 0,75

\section{Estágios:}

\begin{tabular}{|c|c|}
\hline Escore & $\begin{array}{l}\text { Valores de Referência } \\
\text { Há disponibilidade de: }\end{array}$ \\
\hline 1,00 & $\begin{array}{l}\text { Informação sobre serviços de transporte público, canais de } \\
\text { comunicação para denúncias e reclamações, informações sobre } \\
\text { condições de trânsito e circulação e informações sobre planos e } \\
\text { projetos de transporte e mobilidade urbana }\end{array}$ \\
\hline 0,75 & $\begin{array}{l}\text { Informação sobre serviços de transporte público, canais de } \\
\text { comunicação para denúncias e reclamações e informações sobre } \\
\text { condições de trânsito e circulação }\end{array}$ \\
\hline 0,50 & $\begin{array}{l}\text { Informação sobre serviços de transporte público e canais de } \\
\text { comunicacão para denúncias e reclamacõos }\end{array}$ \\
\hline 0,25 & Informação sobre serviços de transporte público \\
\hline 0,00 & $\begin{array}{l}\text { Não há disponibilidade de qualquer tipo de informação sobre } \\
\text { transportes e mobilidade para os cidadãos }\end{array}$ \\
\hline
\end{tabular}

\section{SIMULACẼO AMBICIOSA:}

Variação de Estágio: $2 \times 0,25=0,50$

Escore a ser atingido: $0,75+0,50=1,00$ (excede o valor máximo)

Valor normalizado: 1,00

Ação consequente: Disponibilizar informações sobre planos e projetos de transportes e mobilidade urbana. 


\section{SIMULACÃO CONSERVADORA:}

Variação de Estágio: $1 \times 0,25=0,25$

Escore a ser atingido: $0,75+0,25=1,00$

Valor normalizado: 1,00

Ação consequente: Disponibilizar informações sobre planos e projetos de transportes e mobilidade urbana. 


\begin{tabular}{|l|l|}
\hline DOMÍNIO & Aspectos Sociais \\
\hline TEMA & Inclusão Social \\
\hline INDICADOR 3.2.1 & Equidade vertical (renda) \\
\hline
\end{tabular}

Definição: Razão entre o número médio de viagens diárias dos moradores de domicílios mais pobres, entendidos como os domicílios com renda até 3 salários mínimos, e dos moradores dos domicílios mais ricos, entendidos como os domicílios com renda superior a 20 salários mínimos.

Escore: 0,66

Normalização: 0,66

Estágios:

\begin{tabular}{|l|l|}
\hline Escore & $\begin{array}{l}\text { Valores de Referência } \\
\text { Razão entre o número médio de viagens diárias dos moradores de } \\
\text { domicílios mais pobres e o número médio de viagens diárias dos } \\
\text { moradores de domicílios mais ricos }\end{array}$ \\
\hline 1,00 & 1,00 ou mais \\
\hline 0,75 & 0,75 \\
\hline 0,50 & 0,50 \\
\hline 0,25 & 0,25 \\
\hline 0,00 & 0 \\
\hline
\end{tabular}

\section{SIMULACÃO AMBICIOSA:}

Variação de Estágio: $0,5 \times 0,25=0,125$

Escore a ser atingido: $0,66+0,125=0,79$

Valor normalizado: 0,79

Ação consequente: Elevar o número de viagens das classes de até 3 SM de 1,59 para 1,89 por habitante.

\section{SIMULACÃO CONSERVADORA:}

Variação de Estágio: Não há variação

Escore a ser atingido: -

Valor normalizado: -

Ação consequente: Manter o número de viagens das classes de até $3 \mathrm{SM}$ em uma proporção de, pelo menos, $66 \%$ do número de viagens entre as classes mais ricas. 


\begin{tabular}{|l|l|}
\hline DOMíNIO & Aspectos Sociais \\
\hline TEMA & Educação e cidadania \\
\hline INDICADOR 3.3.1 & Educação para o desenvolvimento sustentável \\
\hline
\end{tabular}

Definição: Existência de ações continuadas de formação e sensibilização, equipamentos públicos específicos, programas e projetos desenvolvidos pelo município em matéria de educação para o desenvolvimento sustentável.

Escore: $O$ município não dispõe de ações continuadas de formação em matéria de desenvolvimento sustentável, mas promove campanhas de sensibilização para o desenvolvimento sustentável.

Normalização: 0,25

Estágios:

\begin{tabular}{|c|l|}
\hline Escore & $\begin{array}{l}\text { Valores de Referência } \\
\text { O município dispõe de: }\end{array}$ \\
\hline 1,00 & $\begin{array}{l}\text { Equipamentos específicos, ações de formação continuada para } \\
\text { crianças, jovens e adultos e promove campanhas de sensibilização } \\
\text { para o desenvolvimento sustentável }\end{array}$ \\
\hline 0,75 & $\begin{array}{l}\text { Ações de formação continuada para crianças, jovens e adultos e } \\
\text { promove campanhas de sensibilização para o desenvolvimento } \\
\text { sustentável }\end{array}$ \\
\hline 0,50 & $\begin{array}{l}\text { Ações de formação continuada somente para crianças e promove } \\
\text { campanhas de sensibilização para o desenvolvimento sustentável }\end{array}$ \\
\hline 0,25 & $\begin{array}{l}\text { Promove campanhas de sensibilização para o desenvolvimento } \\
\text { sustentável }\end{array}$ \\
\hline 0,00 & $\begin{array}{l}\text { O município não dispõe de nenhuma ação em matéria de } \\
\text { educação para o desenvolvimento sustentável }\end{array}$ \\
\hline
\end{tabular}

\section{SIMULACÃO AMBICIOSA:}

Variação de Estágio: $2 \times 0,25=0,50$

Escore a ser atingido: $0,25+0,50=0,75$

Valor normalizado: 0,75

Ação consequente: Promover ações de formação continuada sobre desenvolvimento sustentável para crianças, jovens e adultos.

\section{SIMULACÃO CONSERVADORA:}

Variação de Estágio: 1 × 0,25 =0,25 
Escore a ser atingido: $0,25+0,25=0,50$

Valor normalizado: 0,50

Ação consequente: Promover ações de formação continuada pelo menos para crianças. 


\begin{tabular}{|l|l|}
\hline DOMÍNIO & Aspectos Sociais \\
\hline TEMA & Participação Popular \\
\hline INDICADOR 3.4.1 & Participação na tomada de decisão \\
\hline
\end{tabular}

Definição: Incentivo e viabilização por parte da administração municipal para a participação popular nos processos de elaboração, implementação e monitoramento das políticas, ações e projetos de transporte e mobilidade urbana.

Escore: Ocorreu incentivo e viabilização por parte da administração municipal a participação popular no desenvolvimento de políticas, ações e projetos de transportes, mobilidade e desenvolvimento urbano em duas de suas etapas (elaboração, implementação e monitoramento).

Normalização: 0,66

Estágios:

\begin{tabular}{|c|l|}
\hline Escore & $\begin{array}{l}\text { Valores de Referência } \\
\text { A administração municipal: }\end{array}$ \\
\hline 1,00 & $\begin{array}{l}\text { Incentivou e viabilizou a participação popular no desenvolvimento } \\
\text { de políticas, ações e projetos de transportes, mobilidade e } \\
\text { desenvolvimento urbano, em todas as suas etapas (elaboração, } \\
\text { implementação e monitoramento) }\end{array}$ \\
\hline 0,66 & $\begin{array}{l}\text { Incentivou e viabilizou a participação popular no desenvolvimento } \\
\text { de políticas, ações e projetos de transportes, mobilidade e } \\
\text { desenvolvimento urbano, em duas de suas etapas (elaboração, } \\
\text { implementação ou monitoramento) }\end{array}$ \\
\hline 0,33 & $\begin{array}{l}\text { Incentivou e viabilizou a participação popular no desenvolvimento } \\
\text { de políticas, ações e projetos de transportes, mobilidade e } \\
\text { desenvolvimento urbano, somente em uma de suas etapas } \\
\text { (elaboração, implementação ou monitoramento) }\end{array}$ \\
\hline 0,00 & $\begin{array}{l}\text { Não incentivou nem viabilizou a participação popular no } \\
\text { desenvolvimento de quaisquer políticas, ações e projetos de } \\
\text { transportes, mobilidade e desenvolvimento urbano }\end{array}$ \\
\hline
\end{tabular}

SIMULACÃO AMBICIOSA:

Variação de Estágio: $1,5 \times 0,33=0,495$

Escore a ser atingido: $0,66+0,495=1,00$ (Excede o valor máximo)

Valor normalizado: 1,00 
Ação consequente: A Adm. Municipal deve incentivar e viabilizar a participação popular também na fase de monitoramento das ações e projetos de transportes.

\section{SIMULACÃO CONSERVADORA:}

Variação de Estágio: 0,5 x 0,33 = 0,165 (por ser um estágio quantitativo, não há variação)

\section{Escore a ser atingido: -}

Valor normalizado: 0,66

Ação consequente: Manter as condições atuais de participação popular pelo menos nas etapas de elaboração e implementação de ações e projetos de transportes. 


\begin{tabular}{|l|l|}
\hline DOMÍNIO & Aspectos Sociais \\
\hline TEMA & Qualidade de Vida \\
\hline INDICADOR 3.5.1 & Qualidade de Vida \\
\hline
\end{tabular}

Definição: Porcentagem da população satisfeita com a cidade como local para viver.

Observação: A insuficiência de dados impossibilitou a execução do cálculo deste indicador. Nos cenários também não foram calculados para evitar a redistribuição dos pesos entre os indicadores.

\section{Escore: -}

Normalização: -

Estágios:

\begin{tabular}{|c|l|}
\hline Escore & $\begin{array}{l}\text { Valores de Referência } \\
\text { Porcentagem da população (ou dos entrevistados) considera a } \\
\text { cidade como um lugar "bom" e "excelente" para se viver }\end{array}$ \\
\hline 1,00 & $100 \%$ \\
\hline 0,75 & $75 \%$ \\
\hline 0,50 & $50 \%$ \\
\hline 0,25 & $25 \%$ \\
\hline 0,00 & 0 \\
\hline
\end{tabular}

SIMULACÃO AMBICIOSA:

Variação de Estágio: 1,25

Escore a ser atingido: -

Valor normalizado: -

SIMULAÇ̃̃O CONSERVADORA:

Variação de Estágio: 0,1

Escore a ser atingido: -

Valor normalizado: -

Ação consequente: - 


\begin{tabular}{|l|l|}
\hline DOMÍNIO & Aspectos Políticos \\
\hline TEMA & Integração de ações políticas \\
\hline INDICADOR 4.1.1 & Integração entre níveis de governo \\
\hline
\end{tabular}

Definição: Frequência e grau de integração de ações, programas e projetos de transportes, mobilidade e desenvolvimento urbano desenvolvidos pelo município, em conjunto com o governo estadual e/ou federal.

Escore: Frequentes, envolvendo os governos municipal, estadual e federal. Normalização: 0,75

Estágios:

\begin{tabular}{|c|l|}
\hline Escore & $\begin{array}{l}\text { Valores de Referência } \\
\text { As ações integradas são: }\end{array}$ \\
\hline 1,00 & $\begin{array}{l}\text { Muito frequentes, envolvendo os governos municipal, estadual e } \\
\text { federal }\end{array}$ \\
\hline 0,75 & Frequentes, envolvendo os governos municipal, estadual e federal \\
\hline 0,50 & $\begin{array}{l}\text { Pouco frequentes, envolvendo os governos municipal, estadual e } \\
\text { federal }\end{array}$ \\
\hline 0,25 & $\begin{array}{l}\text { Pouco frequentes, envolvendo somente os governos municipal e } \\
\text { estadual }\end{array}$ \\
\hline 0,00 & $\begin{array}{l}\text { As ações integradas entre os governos municipal, estadual e } \\
\text { federal são aras no município }\end{array}$ \\
\hline
\end{tabular}

\section{SIMULACÃO AMBICIOSA:}

Variação de Estágio: $1,75 \times 0,25=0,425$

Escore a ser atingido: $0,75+0,425=1,00$ (Excede o valor máximo)

Valor normalizado: 1,00

Ação consequente: Tornar muito frequentes as ações integradas envolvendo as três esferas de governo.

\section{SIMULACÃO CONSERVADORA:}

Variação de Estágio: $0,75 \times 0,25=0,19$

Escore a ser atingido: $0,75+0,19=0,94$ (por ser quantitativo, aproximou-se de 1,00)

\section{Valor normalizado: 1,00}


Ação consequente: Tornar muito frequentes as ações integradas envolvendo as três esferas de governo. 


\begin{tabular}{|l|l|}
\hline DOMÍNIO & Aspectos Políticos \\
\hline TEMA & Integração de Ações Políticas \\
\hline INDICADOR 4.1.2 & Parcerias público privadas \\
\hline
\end{tabular}

Definição: Ações, projetos, serviços ou infraestrutura de transporte urbano viabilizados por meio de parcerias entre o governo municipal e entidades privadas.

Escore: As parcerias público-privadas para projetos de transportes e mobilidade urbana encontram-se em preparação no município.

Normalização: 0,50

Estágios:

\begin{tabular}{|c|l|}
\hline Escore & $\begin{array}{l}\text { Valores de Referência } \\
\text { Projetos de transportes e mobilidade urbana por meio de parcerias } \\
\text { público-privadas: }\end{array}$ \\
\hline 1,00 & Já foram implementados no município \\
\hline 0,50 & Encontram-se em preparação no município \\
\hline 0,00 & Não estão previstos nem foram implementados no município \\
\hline
\end{tabular}

\section{SIMULACÃO AMBICIOSA:}

Variação de Estágio: $1,75 \times 0,50=0,875$

Escore a ser atingido: $0,50+0,875=1,00$ (valor excede o máximo)

Valor normalizado: 1,00

Ação consequente: Implementar as parcerias público-privadas para projetos de transportes e mobilidade urbana.

\section{SIMULACÃO CONSERVADORA:}

Variação de Estágio: $0,75 \times 0,50=0,375$

Escore a ser atingido: $0,50+0,375=0,875$ (Por ser quantitativo foi aproximado para 1,00)

Valor normalizado: 1,00

Ação consequente: Implementar as parcerias público-privadas para projetos de transportes e mobilidade urbana. 


\begin{tabular}{|l|l|}
\hline DOMÍNIO & Aspectos Políticos \\
\hline TEMA & Captação e Gerenciamento de Recursos \\
\hline INDICADOR 4.2.1 & Captação de recursos \\
\hline
\end{tabular}

Definição: Porcentagem dos recursos municipais para financiamento de projetos de transportes e mobilidade oriundos de taxações aos veículos/usuários, multas ou pedágios urbanos.

Escore: 10\%

Normalização: 0,50

Estágios:

\begin{tabular}{|c|l|}
\hline Escore & $\begin{array}{l}\text { Valores de Referência } \\
\text { Porcentagem dos recursos municipais para transportes e } \\
\text { mobilidade obtidos por meio de taxações, multa ou pedágios } \\
\text { urbanos }\end{array}$ \\
\hline 1,00 & $20 \%$ ou mais \\
\hline 0,75 & $15 \%$ \\
\hline 0,50 & $10 \%$ \\
\hline 0,25 & $5 \%$ \\
\hline 0,00 & 0 \\
\hline
\end{tabular}

\section{SIMULACÃO AMBICIOSA:}

Variação de Estágio: $1,5 \times 5 \%=7,5 \%$

Escore a ser atingido: $10 \%+7,5=17,50 \%$

Valor normalizado: 0,88

Ação consequente: Aumentar de 10 para $17,5 \%$ a porcentagem dos recursos municipais destinados ao financiamento de projetos de transportes e mobilidade.

\section{SIMULACÃO CONSERVADORA:}

Variação de Estágio: $0,25 \times 5 \%=1,25 \%$

Escore a ser atingido: $10 \%+1,25=11,25 \%$

Valor normalizado: 0,56

Ação consequente: Aumentar de 10 para $11,25 \%$ a porcentagem dos recursos municipais destinados ao financiamento de projetos de transportes e mobilidade. 


\begin{tabular}{|l|l|}
\hline DOMÍNIO & Aspectos Políticos \\
\hline TEMA & Captação e Gerenciamento de recursos \\
\hline INDICADOR 4.2.2 & Investimentos em sistemas de transportes \\
\hline
\end{tabular}

Definição: Investimentos em sistemas de transportes e mobilidade urbana feitos pelo município no ano de referência.

Escore: Obras de infraestrutura, investimentos na provisão e melhoria de serviços de transporte coletivo, modos não motorizados de transporte ou ampliação da mobilidade de pessoas com necessidades especiais.

Normalização: 0,75

Estágios:

\begin{tabular}{|c|l|}
\hline Escore & $\begin{array}{l}\text { Valores de Referência } \\
\text { Houve investimentos no ano de referência no município em: }\end{array}$ \\
\hline 1,00 & $\begin{array}{l}\text { Obras de infraestrutura, investimentos na provisão e melhoria de } \\
\text { serviços de transporte coletivo, projetos para os modos não } \\
\text { motorizados de transporte e ampliação da mobilidade de pessoas } \\
\text { com necessidades especiais, além de planos de mobilidade } \\
\text { urbana }\end{array}$ \\
\hline 0,75 & $\begin{array}{l}\text { Obras de infraestrutura, investimentos na provisão e melhoria de } \\
\text { serviços de transporte coletivo, modos não motorizados de } \\
\text { transporte ou ampliação da mobilidade de pessoas com } \\
\text { necessidades especiais }\end{array}$ \\
\hline 0,50 & $\begin{array}{l}\text { Obras de infraestrutura e investimentos na provisão e melhoria de } \\
\text { serviços de transporte coletivo }\end{array}$ \\
\hline 0,25 & $\begin{array}{l}\text { Somente em obras emergenciais, corretivas e preventivas de } \\
\text { infraestrutura de transportes }\end{array}$ \\
\hline 0,00 & $\begin{array}{l}\text { Não houve investimentos em infraestrutura, sistemas de } \\
\text { transportes e mobilidade }\end{array}$ \\
\hline
\end{tabular}

\section{SIMULACÃO AMBICIOSA:}

Variação de Estágio: $1,5 \times 0,25=0,375$

Escore a ser atingido: $0,75+0,375=1,00$ (Excede o valor máximo)

Valor normalizado: 1,00

Ação consequente: Destinar investimentos para a criação de um Plano de Mobilidade Urbana. 


\section{SIMULACÃO CONSERVADORA:}

Variação de Estágio: $0,25 \times 0,25=0,06$ (Não há alteração)

Escore a ser atingido:

Valor normalizado: 0,75

Ação consequente: Manter os investimentos existentes em sistemas de transportes. 


\begin{tabular}{|l|l|}
\hline DOMÍNIO & Aspectos Políticos \\
\hline TEMA & Captação e Gerenciamento de Recursos \\
\hline INDICADOR 4.2.3 & Distribuição dos recursos (coletivo x privado) \\
\hline
\end{tabular}

Definição: Razão entre os investimentos públicos com infraestrutura para o transporte coletivo e infraestrutura para o transporte privado.

Escore: Os investimentos em infraestrutura para transporte coletivo no município no ano de referência foram equivalentes aos investimentos em infraestrutura para o transporte privado.

Normalização: 0,75

Estágios:

\begin{tabular}{|c|l|}
\hline Escore & Valores de Referência \\
\hline 1,00 & $\begin{array}{l}\text { I }>1 \text { Os investimentos em infraestrutura para transporte coletivo no } \\
\text { município no ano de referência foram superiores aos investimentos } \\
\text { em infraestrutura para o transporte privado }\end{array}$ \\
\hline 0,75 & $\begin{array}{l}\mathrm{I}=1 \text { Os investimentos em infraestrutura para transporte coletivo no } \\
\text { município no ano de referência foram equivalentes aos } \\
\text { investimentos em infraestrutura para o transporte privado }\end{array}$ \\
\hline 0,50 & $\begin{array}{l}0,5<\mathrm{I}<1 \text { Houve investimentos em infraestrutura para transporte } \\
\text { coletivo no município no ano de referência, porém, estes foram um } \\
\text { pouco inferiores aos investimentos em infraestrutura para o } \\
\text { transporte privado }\end{array}$ \\
\hline 0,25 & $\begin{array}{l}0<\mathrm{I} \leq 0,5 \text { Houve investimentos em infraestrutura para transporte } \\
\text { coletivo no município no ano de referência, porém, estes foram } \\
\text { bastante inferiores aos investimentos em infraestrutura para o } \\
\text { transporte privado }\end{array}$ \\
\hline $\begin{array}{l}\mathrm{I}=0 \text { Não houve investimentos em infraestrutura para transporte } \\
\text { coletivo no município no ano de referência. Os recursos foram } \\
\text { destinados à provisão, ampliação e manutenção de vias de uso } \\
\text { predominante de automóveis }\end{array}$ \\
\hline
\end{tabular}

\section{SIMULACÃO AMBICIOSA:}

Variação de Estágio: $0,5 \times 0,5=0,25$

Escore a ser atingido: $1+0,25=1,25 \rightarrow$ Corresponde a $I>1$

Valor normalizado: 1,00

Ação consequente: Os investimentos em infraestrutura para 0 transporte coletivo devem superar os investimentos em transportes privados. 


\section{SIMULACÃO CONSERVADORA:}

Variação de Estágio: Não há.

Escore a ser atingido: -

Valor normalizado:

Ação consequente: Manter os investimentos em infraestrutura para 0 transporte coletivo equivalentes aos investimentos em transportes privados. 


\begin{tabular}{|l|l|}
\hline DOMÍNIO & Aspectos Políticos \\
\hline TEMA & Captação e Gerenciamento de Recursos \\
\hline INDICADOR 4.2.4 & $\begin{array}{l}\text { Distribuição dos recursos (motorizados x não } \\
\text { motorizados) }\end{array}$ \\
\hline
\end{tabular}

Definição: Razão entre os gastos públicos com infraestrutura para os modos não motorizados e infraestrutura para os modos motorizados de transporte.

Escore: Houve investimentos em infraestrutura para modos não motorizados de transporte no município no ano de referência, porém, estes foram bastante inferiores aos investimentos em infraestrutura para os modos motorizados.

Normalização: 0,25

Estágios:

\begin{tabular}{|c|l|}
\hline Escore & Valores de Referência \\
\hline 1,00 & $\begin{array}{l}\mathrm{I}>1 \text { Os investimentos em infraestrutura para modos não } \\
\text { motorizados de transporte no município no ano de referência foram } \\
\text { superiores aos investimentos em infraestrutura para os modos } \\
\text { motorizados }\end{array}$ \\
\hline $\begin{array}{l}\mathrm{I}=1 \text { Os investimentos em infraestrutura para modos não } \\
\text { motorizados de transporte no município no ano de referência foram } \\
\text { equivalentes aos investimentos em infraestrutura para os modos } \\
\text { motorizados }\end{array}$ \\
\hline 0,50 & $\begin{array}{l}0,5<\mathrm{I}<1 \text { Houve investimentos em infraestrutura para modos não } \\
\text { motorizados de transporte no município no ano de referência, } \\
\text { porém, estes foram um pouco inferiores aos investimentos em } \\
\text { infraestrutura para os modos motorizados }\end{array}$ \\
\hline 0,25 & $\begin{array}{l}0<\mathrm{I} \leq 0,5 \text { Houve investimentos em infraestrutura para modos não } \\
\text { motorizados de transporte no município no ano de referência, } \\
\text { porém, estes foram bastante inferiores aos investimentos em } \\
\text { infraestrutura para os modos motorizados }\end{array}$ \\
\hline $\begin{array}{l}\mathrm{I}=0 \text { Não houve investimentos em infraestrutura para modos não } \\
\text { motorizados de transporte no munićpio no ano de referência. Os } \\
\text { recursos foram destinados a provisão, ampliação e manutenção de } \\
\text { vias de uso de veículos }\end{array}$ \\
\hline
\end{tabular}

\section{SIMULACÃO AMBICIOSA:}

Variação de Estágio: $0,5 \times 0,5=0,25$

Escore a ser atingido: $0,25+0,25=0,50 \rightarrow 0<1 \leq 0,5$

Valor normalizado: 0,25 (Não há variação) 
Ação consequente: Destinar mais recursos públicos à infraestruturas para modos não motorizados.

\section{SIMULACÃO CONSERVADORA:}

Variação de Estágio: Não há.

Escore a ser atingido: -

Valor normalizado: -

Ação consequente: Manter os investimentos em infraestrutura para modos não motorizados em uma quantidade de, pelo menos, $50 \%$ dos investimentos em infraestrutura para modos motorizados. 


\begin{tabular}{|l|l|}
\hline DOMÍNIO & Aspectos Políticos \\
\hline TEMA & Política de mobilidade urbana \\
\hline INDICADOR 4.3.1 & Política de mobilidade urbana \\
\hline
\end{tabular}

Definição: Existência ou desenvolvimento de política de transportes e mobilidade em nível local, especialmente no que diz respeito à elaboração do Plano Diretor de Transporte e da Mobilidade.

Escore: $O$ município não possui qualquer política ou plano de mobilidade urbana em implantação ou em desenvolvimento

Normalização: 0,00

\section{Estágios:}

\begin{tabular}{|c|l|}
\hline Escore & $\begin{array}{l}\text { Valores de Referência } \\
\text { O município encontra-se no seguinte estágio no ano de referência: }\end{array}$ \\
\hline 1,00 & $\begin{array}{l}\text { Fase de implantação e efetivacaão do Plano Diretor de Transporte } \\
\text { e da Mobilidade ou outro instrumento referente à política de } \\
\text { mobilidade urbana }\end{array}$ \\
\hline 0,75 & $\begin{array}{l}\text { Fase de institucionalização do Plano Diretor de Transporte e da } \\
\text { Mobilidade ou outro instrumento referente à política de mobilidade } \\
\text { urbana }\end{array}$ \\
\hline 0,50 & $\begin{array}{l}\text { Fase de desenvolvimento de estudos e projetos relacionados à } \\
\text { elaboração do Plano Diretor de Transporte e da Mobilidade ou } \\
\text { outro instrumento referente à política de mobilidade urbana }\end{array}$ \\
\hline 0,25 & $\begin{array}{l}\text { Fase de mobilização ou contratação de consultoria especializada } \\
\text { para elaboração do Plano Diretor de Transporte e da Mobilidade } \\
\text { ou outro instrumento referente à política de mobilidade urbana }\end{array}$ \\
\hline 0,00 & $\begin{array}{l}\text { O município não possui qualquer política ou plano de mobilidade } \\
\text { urbana em implantação ou em desenvolvimento }\end{array}$ \\
\hline
\end{tabular}

\section{SIMULACÃO AMBICIOSA:}

Variação de Estágio: $0,5 \times 0,25=0,125$ (aproximou-se de 0,25 )

Escore a ser atingido: $0,00+0,25=0,25$

Valor normalizado: 0,25

Ação consequente: Mobilizar ou contratar consultoria especializada para elaboração do Plano Diretor de Transportes e de Mobilidade.

\section{SIMULAÇ̃̃O CONSERVADORA:}

Variação de Estágio: Não há. 
Escore a ser atingido: -

Valor normalizado: -

Ação consequente: - 


\begin{tabular}{|l|l|}
\hline DOMÍNIO & Infraestrutura de Transportes \\
\hline TEMA & Provisão e manutenção da infraestrutura de transportes \\
\hline INDICADOR 5.1.1 & Densidade e conectividade da rede viária \\
\hline
\end{tabular}

Definição: Densidade e conectividade da rede viária urbana.

Escore: Alta/Alta

Normalização: 1,00

Estágios:

\begin{tabular}{|c|l|}
\hline Escore & $\begin{array}{l}\text { Valores de Referência } \\
\text { Densidade: Baixa }<10 \mathrm{~km} / \mathrm{km}^{2} \\
\text { Alta }>10 \mathrm{~km} / \mathrm{km}\end{array}$ \\
$\begin{array}{r}\text { Conectividade: Baixa }<50 \% \text { dos nós } \\
\text { Alta }>50 \% \text { dos nós }\end{array}$ \\
\hline 1,00 & Alta/Alta $\quad$ \\
\hline 0,66 & Baixa/Alta \\
\hline 0,33 & Alta/Baixa \\
\hline 0,00 & Baixa/Baixa \\
\hline
\end{tabular}

\section{SIMULACÃO AMBICIOSA:}

Variação de Estágio: 1,75

Escore a ser atingido: Está no máximo.

Valor normalizado: 1,00

Ação consequente: Manter a conectividade das novas vias e criar novas vias em bairros novos.

\section{SIMULACÃO CONSERVADORA:}

Variação de Estágio: 0,75

Escore a ser atingido: Está no máximo

Valor normalizado: 1,00

Ação consequente: Manter a conectividade das novas vias e criar novas vias em bairros novos. 


\begin{tabular}{|l|l|}
\hline DOMÍNIO & Infraestrutura de Transportes \\
\hline TEMA & Provisão e manutenção da infraestrutura de transportes \\
\hline INDICADOR 5.1.2 & Vias pavimentadas \\
\hline
\end{tabular}

Definição: Extensão de vias pavimentadas em relação à extensão total do sistema viário urbano.

Escore: 96,00

Normalização: 0,96

Estágios:

\begin{tabular}{|c|l|}
\hline Escore & $\begin{array}{l}\text { Valores de Referência } \\
\text { Porcentagem do sistema viário urbano pavimentado. }\end{array}$ \\
\hline 1,00 & $100 \%$ \\
\hline 0,75 & $77,5 \%$ \\
\hline 0,50 & $55 \%$ \\
\hline 0,25 & $32,5 \%$ \\
\hline 0,00 & Até $10 \%$ \\
\hline
\end{tabular}

\section{SIMULACC̃̃O AMBICIOSA:}

Variação de Estágio: $1,25 \times 22,5 \%=28,125 \%$

Escore a ser atingido: $96,00 \%+28,12=100 \%$ (excede o valor máximo)

Valor normalizado: 1,00

Ação consequente: Pavimentar os $31 \mathrm{Km}$ de vias não pavimentadas da cidade bem como novas vias ${ }^{10}$.

\section{SIMULAC̄̃O CONSERVADORA:}

Variação de Estágio: $0,1 \times 22,5 \%=2,25 \%$

Escore a ser atingido: $96,00 \%+2,25=98,25 \%$

Valor normalizado: 0,98

Ação consequente: Pavimentar mais $16 \mathrm{Km}$ de vias não pavimentadas da cidade bem como novas vias ${ }^{10}$.

\footnotetext{
${ }^{10}$ Baseado nos dados de vias pavimentadas em 2008.
} 


\begin{tabular}{|l|l|}
\hline DOMÍNIO & Infraestrutura de Transportes \\
\hline TEMA & Provisão e manutenção da infraestrutura de transportes \\
\hline INDICADOR 5.1.3 & Despesas com manutenção da infraestrutura \\
\hline
\end{tabular}

Definição: Forma de aplicação dos recursos públicos na manutenção e conservação da infraestrutura para todos os modos de transportes.

Escore: 0,75

Normalização: 0,75

Estágios:

\begin{tabular}{|c|l|}
\hline Escore & Valores de Referência \\
\hline 1,00 & $\begin{array}{l}\text { As despesas com manutenção e conservação de infraestrutura de } \\
\text { transportes contemplaram intervenções de caráter emergencial, } \\
\text { manutenção corretiva e preventiva das infraestruturas existentes, } \\
\text { representando mais de 50\% do total de recursos municipais } \\
\text { investidos em sistemas de transportes e mobilidade no ano de } \\
\text { referência }\end{array}$ \\
\hline 0,75 & $\begin{array}{l}\text { As despesas com manutenção e conservação de infraestrutura de } \\
\text { transportes contemplaram intervenções de caráter emergencial, } \\
\text { manutenção corretiva e preventiva das infraestruturas existentes, } \\
\text { representando aproximadamente 50\% do total de recursos } \\
\text { municipais investidos em sistemas de transportes e mobilidade no } \\
\text { ano de referência }\end{array}$ \\
\hline 0,50 & $\begin{array}{l}\text { As despesas com manutenção e conservação de infraestrutura de } \\
\text { transportes contemplaram intervenções de caráter emergencial, } \\
\text { manutenção corretiva e preventiva das infraestruturas existentes, } \\
\text { porém, estas despesas representaram menos de 50\% do total de } \\
\text { recursos municipais investidos em sistemas de transportes e } \\
\text { mobilidade no ano de referência }\end{array}$ \\
\hline 0,25 & $\begin{array}{l}\text { As despesas com manutenção e conservação de infraestrutura de } \\
\text { transportes se limitaram a intervenções de caráter emergencial, } \\
\text { representando menos de 50\% do total de recursos municipais } \\
\text { investidos em sistemas de transportes e mobilidade no ano de } \\
\text { referência }\end{array}$ \\
\hline 0,00 & $\begin{array}{l}\text { Não houve qualquer despesa com manutenção e conservação da } \\
\text { infraestrutura de transportes no ano de referência no município }\end{array}$ \\
\hline
\end{tabular}

SIMULAÇ̃̃O AMBICIOSA:

Variação de Estágio: $1,5 \times 0,25=0,375$

Escore a ser atingido: $0,75+0,375=1,00$ (valor excede o máximo)

Valor normalizado: 1,00 
Ação consequente: As despesas com manutenção e conservação de infraestrutura de transportes devem ser de mais que $50 \%$ dos recursos municipais investidos em transportes e mobilidade.

\section{SIMULACÃO CONSERVADORA:}

Variação de Estágio: $0,25 \times 0,25=0,0625$ (o valor é muito baixo, então não altera o escore).

\section{Escore a ser atingido: -}

Valor normalizado: 0,75

Ação consequente: Dentre as despesas com manutenção e conservação de infraestrutura de transportes, aproximadamente $50 \%$ dos recursos municipais devem continuar sendo investidos em transportes e mobilidade. 


\begin{tabular}{|l|l|}
\hline DOMÍNIO & Infraestrutura de Transportes \\
\hline TEMA & Provisão e manutenção da infraestrutura de transportes \\
\hline INDICADOR 5.1.4 & Sinalização Viária \\
\hline
\end{tabular}

Definição: Avaliação por parte da população sobre a qualidade da sinalização viária implantada na área urbana do município.

Observação: $A$ insuficiência de dados impossibilitou a execução do cálculo deste indicador. Deve ser feita uma pesquisa de opinião para obter saber o nível de qualidade da sinalização viária urbana. Nos cenários também não foram calculados para evitar a redistribuição dos pesos entre os indicadores.

\section{Escore: -}

Normalização: -

Estágios:

\begin{tabular}{|c|l|}
\hline Escore & $\begin{array}{l}\text { Valores de Referência } \\
\text { A maioria da população (ou dos entrevistados) classifica a } \\
\text { sinalização viária como: }\end{array}$ \\
\hline 1,00 & $\begin{array}{l}\text { "Excelente" para os modos motorizados e não motorizados de } \\
\text { transporte }\end{array}$ \\
\hline 0,80 & "Excelente" somente para os modos motorizados de transporte \\
\hline 0,60 & "Boa" para os modos motorizados não motorizados de transporte \\
\hline 0,40 & "Boa" somente para os modos motorizados de transporte \\
\hline 0,20 & "Ruim" somente para os modos motorizados de transporte \\
\hline 0,00 & $\begin{array}{l}\text { "Ruim" para os modos motorizados e não motorizados de } \\
\text { transporte }\end{array}$ \\
\hline
\end{tabular}

SIMULACÃO AMBICIOSA:

Variação de Estágio: 1,75

Escore a ser atingido: -

Valor normalizado: -

\section{SIMULACÃO CONSERVADORA:}

Variação de Estágio: 0,75

Escore a ser atingido: -

Valor normalizado: - 


\begin{tabular}{|l|l|}
\hline DOMINIIO & Infraestrutura de Transportes \\
\hline TEMA & Distribuição da infraestrutura de transportes \\
\hline INDICADOR 5.2.1 & Vias para transporte coletivo \\
\hline
\end{tabular}

Definição: Porcentagem da área urbana da cidade atendida por vias exclusivas ou preferenciais para transporte coletivo por ônibus.

Escore: $81,8 \%$

Normalização: 0,82

Estágios:

\begin{tabular}{|c|l|}
\hline Escore & $\begin{array}{l}\text { Valores de Referência } \\
\text { Porcentagem da área urbana do município é atendida por vias } \\
\text { exclusivas ou preferenciais para transporte coletivo por ônibus e } \\
\text { linhas alimentadoras integradas }\end{array}$ \\
\hline 1,00 & $100 \%$ \\
\hline 0,75 & $75 \%$ \\
\hline 0,50 & $50 \%$ \\
\hline 0,25 & $25 \%$ \\
\hline 0,00 & 0 \\
\hline
\end{tabular}

\section{SIMULAC̄̃̃O AMBICIOSA:}

Variação de Estágio: $1,25 \times 25 \%=31,25 \%$

Escore a ser atingido: $81,8 \%+31,25 \%=100 \%$ (excede o valor máximo)

Valor normalizado: 1,00

Ação consequente: Estender as linhas de transportes coletivo para os 12,25 $\mathrm{km}^{2}$ do tecido urbano não cobertos por um raio de 500 metros de linhas troncais ou 300 metros de linhas alimentadoras.

\section{SIMULACÃO CONSERVADORA:}

Variação de Estágio: $0,1 \times 25 \%=2,5 \%$

Escore a ser atingido: $81,8 \%+2,5 \%=84,30 \%$

Valor normalizado: 0,84

Ação consequente: Estender as linhas de transportes coletivo para mais 1,7 km2 do tecido urbano não cobertos por um raio de 500 metros de linhas troncais ou 300 metros de linhas alimentadoras. 


\begin{tabular}{|l|l|}
\hline DOMÍNIO & Modos Não motorizados \\
\hline TEMA & Transporte cicloviário \\
\hline INDICADOR 6.1.1 & Extensão e conectividade de ciclovias \\
\hline
\end{tabular}

Definição: Cobertura e conectividade da rede de vias para bicicleta.

Escore: 0,4\%

Normalização: 0,25

Estágios:

\begin{tabular}{|c|l|}
\hline Escore & Valores de Referência \\
\hline 1,00 & $\begin{array}{l}\text { Mais de 25\% do sistema viário urbano apresenta ciclovia ou } \\
\text { ciclofaixas e a rede apresenta alta conectividade }\end{array}$ \\
\hline 0,75 & $\begin{array}{l}\text { Mais de 25\% do sistema viário urbano apresenta ciclovia ou } \\
\text { ciclofaixas, porém, a rede apresenta baixa conectividade }\end{array}$ \\
\hline 0,50 & $\begin{array}{l}\text { Até } 25 \% \text { do sistema viário urbano apresenta ciclovia ou ciclofaixas } \\
\text { e a rede apresenta alta conectividade }\end{array}$ \\
\hline 0,25 & $\begin{array}{l}\text { Até } 25 \% \text { do sistema viário urbano apresenta ciclovia ou ciclofaixas, } \\
\text { porém, a rede apresenta baixa conectividade }\end{array}$ \\
\hline 0,00 & Não há no município nenhum trecho de ciclovia ou ciclofaixa \\
\hline
\end{tabular}

\section{SIMULAČ̃̃ AMBICIOSA:}

Variação de Estágio: $0,5 \times 0,25=0,125$ (aproximou-se para 1 estagio - 0,25)

Escore a ser atingido: $0,25+0,25=0,5$

Valor normalizado: 0,50

Ação consequente: Implantar ciclovias e aumentar a conectivade entre as existentes.

\section{SIMULAÇ̃̃O CONSERVADORA:}

Variação de Estágio: Não há.

Escore a ser atingido: -

Valor normalizado: 0,25

Ação consequente: Manter as ciclovias e a conectivade entre as existentes. 


\begin{tabular}{|l|l|}
\hline DOMÍNIO & Modos Não motorizados \\
\hline TEMA & Transporte cicloviário \\
\hline INDICADOR 6.1.2 & Frota de bicicletas \\
\hline
\end{tabular}

Definição: Número de bicicletas por 100 habitantes no município.

Observação: $A$ insuficiência de dados impossibilitou a execução do cálculo deste indicador. Levantar o número de bicicletas por grupo de 100 habitantes. Nos cenários também não foram calculados para evitar a redistribuição dos pesos entre os indicadores.

Escore: -

Normalização: -

Estágios:

\begin{tabular}{|c|l|}
\hline Escore & $\begin{array}{l}\text { Valores de Referência } \\
\text { Número de bicicletas por } 100 \text { habitantes do município }\end{array}$ \\
\hline 1,00 & 35 ou mais \\
\hline 0,75 & 30 \\
\hline 0,50 & 25 \\
\hline 0,25 & 20 \\
\hline 0,00 & Até 15 \\
\hline
\end{tabular}

SIMULACÃO AMBICIOSA:

Variação de Estágio: 1,5

Escore a ser atingido: -

Valor normalizado: -

Ação consequente: -

\section{SIMULACÃO CONSERVADORA:}

Variação de Estágio: 0,25

Escore a ser atingido: -

Valor normalizado: -

Ação consequente: - 


\begin{tabular}{|l|l|}
\hline DOMÍNIO & Modos Não motorizados \\
\hline TEMA & Transporte cicloviário \\
\hline INDICADOR 6.1.3 & Estacionamento de bicicletas \\
\hline
\end{tabular}

Definição: Porcentagem dos terminais de transporte público urbano que possuem estacionamento para bicicletas.

Escore: $33 \%$

Normalização: 0,33

Estágios:

\begin{tabular}{|c|l|}
\hline Escore & $\begin{array}{l}\text { Valores de Referência } \\
\text { Porcentagem dos terminais urbanos de transporte público que } \\
\text { apresentam área para estacionamento de bicicletas }\end{array}$ \\
\hline 1,00 & $100 \%$ \\
\hline 0,75 & $75 \%$ \\
\hline 0,50 & $50 \%$ \\
\hline 0,25 & $25 \%$ \\
\hline 0,00 & 0 \\
\hline
\end{tabular}

\section{SIMULACÃO AMBICIOSA:}

Variação de Estágio: $2 \times 25 \%=50 \%$

Escore a ser atingido: $33 \%+50 \%=83 \%$ (Como a cidade possui apenas 3 terminais, foi aproximado para $75 \%$.

Valor normalizado: 0,75

Ação consequente: Implantar bicicletário em todos os três terminais urbanos de transporte público.

\section{SIMULAC̄̃̃O CONSERVADORA:}

Variação de Estágio: $1 \times 25 \%=25 \%$

Escore a ser atingido: $33 \%+25=58 \%$ (porém aproximou-se de $66 \%$ por serem 3 terminais na cidade)

Valor normalizado: 0,66

Ação consequente: Implantar bicicletário em mais um dos três terminais urbanos de transporte público. 


\begin{tabular}{|l|l|}
\hline DOMÍNIO & Modos Não motorizados \\
\hline TEMA & Modos não motorizados \\
\hline INDICADOR 6.2.1 & Vias para pedestres \\
\hline
\end{tabular}

Definição: Cobertura e conectividade da rede de vias para pedestres.

Escore: Avaliação da conectividade da rede de ciclovias com base: na manutenção das características físicas e operacionais da ciclovia; ausência de barreiras físicas que impeçam ou restrinjam os deslocamentos e continuidade baixa conectividade;

Normalização: 0,25

Estágios:

\begin{tabular}{|c|l|}
\hline Escore & Valores de Referência \\
1,00 & $\begin{array}{l}\text { Mais de 25\% do sistema viário urbano é composto por vias } \\
\text { especiais ou preferenciais para pedestres e a rede apresenta alta } \\
\text { conectividade }\end{array}$ \\
\hline 0,75 & $\begin{array}{l}\text { Mais de 25\% do sistema viário urbano é composto por vias } \\
\text { especiais ou preferenciais para pedestres, porém, a rede apresenta } \\
\text { baixa conectividade }\end{array}$ \\
\hline 0,50 & $\begin{array}{l}\text { Até 25\% do sistema viário urbano é composto por vias especiais ou } \\
\text { preferenciais para pedestres e a rede apresenta alta conectividade }\end{array}$ \\
\hline 0,25 & $\begin{array}{l}\text { Até 25\% do sistema viário urbano é composto por vias especiais ou } \\
\text { preferenciais para pedestres, porém, a rede apresenta baixa } \\
\text { conectividade }\end{array}$ \\
\hline 0,00 & Não há no município vias especiais ou preferenciais para pedestres \\
\hline
\end{tabular}

\section{SIMULACÃO AMBICIOSA:}

Variação de Estágio: $1,5 \times 0,25=0,375 \%$

Escore a ser atingido: $0,25+0,375=0,62$ (por ser qualitativo, aproximou-se para 0,75 .

Valor normalizado: 0,75

Ação consequente: Dotar 208 dos $835 \mathrm{~km}$ do sistema viário com vias especiais ou preferenciais para pedestres.

\section{SIMULACÃO CONSERVADORA:}

Variação de Estágio: $0,25 \times 0,25=0,06$ (Por ser pequena, não há variação) Escore a ser atingido: - 
Valor normalizado: 0,25

Ação consequente: Manter as vias especiais ou preferenciais para pedestres existentes. 


\begin{tabular}{|l|l|}
\hline DOMÍNIO & Modos Não motorizados \\
\hline TEMA & Modos não motorizados \\
\hline INDICADOR 6.2.2 & Vias com calçadas \\
\hline
\end{tabular}

Definição: Extensão de vias com calçadas em ambos os lados, com largura superior a 1,20 metros, em relação à extensão total da rede viária principal.

Escore: $91,43 \%$

Normalização: 0,90

Estágios:

\begin{tabular}{|c|l|}
\hline Escore & $\begin{array}{l}\text { Valores de Referência } \\
\text { Porcentagem da rede viária principal que apresenta calçadas em } \\
\text { ambos os lados e com largura igual ou superior a 1,20 metros }\end{array}$ \\
\hline 1,00 & $100 \%$ \\
\hline 0,75 & $77,5 \%$ \\
\hline 0,50 & $55 \%$ \\
\hline 0,25 & $32,5 \%$ \\
\hline 0,00 & Até $10 \%$ \\
\hline
\end{tabular}

\section{SIMULACÃO AMBICIOSA:}

Variação de Estágio: $1,5 \times 22,5 \%=33,75 \%$

Escore a ser atingido: $91,43 \%+33,75=100 \%$ (excede o valor máximo)

Valor normalizado: 1,00

Ação consequente: Construir ou melhorar os 5.703 metros (de um total de $66.537 \mathrm{~m}$ ) de vias que ainda não possuem calçadas adequadas com 1,20 m em ambos os lados.

\section{SIMULAC̄̃̃O CONSERVADORA:}

Variação de Estágio: $0,5 \times 22,5 \%=11,25 \%$

Escore a ser atingido: $91,43+11,25=100 \%$ (excede o valor máximo)

Valor normalizado: 1,00

Ação consequente: Construir ou melhorar os 5.703 metros (de um total de $66.537 \mathrm{~m}$ ) de vias que ainda não possuem calçadas adequadas com 1,20 m em ambos os lados. 


\begin{tabular}{|l|l|}
\hline DOMÍNIO & Modos não motorizados \\
\hline TEMA & Redução de viagens \\
\hline INDICADOR 6.3.1 & Distância de viagem \\
\hline
\end{tabular}

Definição: Distância média de viagens feitas na área urbana ou metropolitana, para todos os modos, em um único sentido, por motivo trabalho ou estudo.

Escore: $2,28 \mathrm{~km}$

Normalização: 0,97

Estágios:

\begin{tabular}{|c|l|}
\hline Escore & $\begin{array}{l}\text { Valores de Referência } \\
\text { Distância média das viagens urbanas e metropolitanas, para } \\
\text { todos os modos, em um único sentido, por motivo trabalho ou } \\
\text { estudo }\end{array}$ \\
\hline 1,00 & Igual ou inferior a $2 \mathrm{~km}$ \\
\hline 0,75 & $4 \mathrm{~km}$ \\
\hline 0,50 & $6 \mathrm{~km}$ \\
\hline 0,25 & $8 \mathrm{~km}$ \\
\hline 0,00 & Maior ou igual a $10 \mathrm{~km}$ \\
\hline
\end{tabular}

\section{SIMULACÃO AMBICIOSA:}

Variação de Estágio: $0,5 \times-2 \mathrm{~km}=-1 \mathrm{~km}$

Escore a ser atingido: $2,28-1 \mathrm{~km}=2 \mathrm{~km}$ (o mínimo exigido para chegar ao máximo escore)

Valor normalizado: 1,00

Ação consequente: Tentar reduzir a média das distâncias das viagens de todos os modos em pelo menos 280 metros.

\section{SIMULACÃO CONSERVADORA:}

Variação de Estágio: Não há.

Escore a ser atingido: -

Valor normalizado: 0,97

Ação consequente: Manter estável a média das distâncias das viagens de todos os modos em 2,28 km. 


\begin{tabular}{|l|l|}
\hline DOMÍNIO & Modos Não motorizados \\
\hline TEMA & Redução de Viagem \\
\hline INDICADOR 6.3.2 & Tempo de Viagem \\
\hline
\end{tabular}

Definição: Tempo médio de viagens feitas na área urbana ou metropolitana, para todos os modos, em um único sentido, por motivo trabalho ou estudo

Escore: 11,04 minutos

Normalização: 1,00

Estágios:

\begin{tabular}{|c|l|}
\hline Escore & $\begin{array}{l}\text { Valores de Referência } \\
\text { Tempo médio de viagem para deslocamentos urbanos e } \\
\text { metropolitanos, por motivo trabalho e estudo, para todos os modos } \\
\text { de transporte }\end{array}$ \\
\hline 1,00 & Igual ou inferior a $20 \mathrm{~min}$ \\
\hline 0,75 & $30 \mathrm{~min}$ \\
\hline 0,50 & $40 \mathrm{~min}$ \\
\hline 0,25 & $50 \mathrm{~min}$ \\
\hline 0,00 & $60 \mathrm{~min}$ ou mais \\
\hline
\end{tabular}

SIMULACÃO AMBICIOSA:

Variação de Estágio: 1,5

Escore a ser atingido: Já está no máximo.

Valor normalizado: 1,00

Ação consequente: Manter a média de tempos de viagens menores que 20 minutos.

\section{SIMULAC̄̃̃O CONSERVADORA:}

Variação de Estágio: 0,5

Escore a ser atingido: Já está no máximo.

Valor normalizado: 1,00

Ação consequente: Manter a média de tempos de viagens menores que 20 minutos. 


\begin{tabular}{|l|l|}
\hline DOMÍNIO & Modos Não motorizados \\
\hline TEMA & Redução de viagens \\
\hline INDICADOR 6.3.3 & Número de viagens \\
\hline
\end{tabular}

Definição: Número médio de viagens diárias por habitante em área urbana ou metropolitana, considerando todos os modos de transporte.

Escore: 1,44 Viagem/Habitante/Dia

Normalização: 0,72

Estágios:

\begin{tabular}{|c|l|}
\hline Escore & $\begin{array}{l}\text { Valores de Referência } \\
\text { Número médio de viagens diárias por habitante }\end{array}$ \\
\hline 1,00 & 2 ou mais \\
\hline 0,75 & 1,5 \\
\hline 0,50 & 1,0 \\
\hline 0,25 & 0,5 \\
\hline 0,00 & Inferior a 0,5 \\
\hline
\end{tabular}

\section{SIMULACC̃̃O AMBICIOSA:}

Variação de Estágio: $1,5 \times 0,5$ viagem $/ \mathrm{hab}=0,75$ viagem $/ \mathrm{hab}$

Escore a ser atingido: $1,44+0,75=2,19$ viagens/hab (adotamos 2,00 pois atinge o máximo escore)

Valor normalizado: 1,00

Ação consequente: Incentivar para que a média do número de viagens por habitantes chegue a 2 ou mais viagens por dia.

\section{SIMULACÃO CONSERVADORA:}

Variação de Estágio: $0,25 \times 0,5$ viagens $/ \mathrm{hab}=0,125$ viagens $/ \mathrm{hab}$

Escore a ser atingido: $1,44+0,125=1,57$ viagens/hab

Valor normalizado: 0,78

Ação consequente: Incentivar para que a média do número de viagens por habitantes chegue a 1,57 ou mais viagens por dia. 


\begin{tabular}{|l|l|}
\hline DOMÍNIO & Modos Não motorizados \\
\hline TEMA & Redução de viagens \\
\hline INDICADOR 6.3.4 & Ações para reduções do tráfego motorizado \\
\hline
\end{tabular}

Definição: Políticas, estratégias ou ações empreendidas pelo município com objetivo de reduzir o tráfego motorizado.

Escore: Não foi desenvolvido ou implantado nenhum mecanismo visando à redução do tráfego motorizado no município até o presente momento.

Normalização: 0,00

Estágios:

\begin{tabular}{|c|l|}
\hline Escore & $\begin{array}{l}\text { Valores de Referência } \\
\text { Foram implantados no município: }\end{array}$ \\
\hline 1,00 & $\begin{array}{l}\text { Campanha educativa, rodízio veicular, delimitação de áreas com } \\
\text { restrição para circulação de veículos e pedágio urbano }\end{array}$ \\
\hline 0,75 & $\begin{array}{l}\text { Campanha educativa, rodízio veicular e delimitação de áreas com } \\
\text { restrição para circulação de veículos }\end{array}$ \\
\hline 0,50 & Campanha educativa e rodízio veicular \\
\hline 0,25 & Apenas campanha educativa \\
\hline 0,00 & $\begin{array}{l}\text { Não foi desenvolvido ou implantado nenhum mecanismo visando a } \\
\text { redução do tráfego motorizado no município no ano de referência }\end{array}$ \\
\hline
\end{tabular}

\section{SIMULACÃO AMBICIOSA:}

Variação de Estágio: $0,5 \times 0,25=0,125$ (aproximou-se para 0,25 por ser qualitativo)

Escore a ser atingido: $0,00+0,25=0,25$

Valor normalizado: 0,25

Ação consequente: Promover campanhas educativas visando a redução do tráfego motorizado no município.

\section{SIMULAÇÃO CONSERVADORA:}

Variação de Estágio: Não há.

\section{Escore a ser atingido: -}

Valor normalizado: - 


\begin{tabular}{|l|l|}
\hline DOMÍNIO & Planejamento Integrado \\
\hline TEMA & Capacitação de gestores \\
\hline INDICADOR 7.1.1 & Nível de formação de técnicos e gestores \\
\hline
\end{tabular}

Definição: Porcentagem de técnicos e gestores de órgãos de planejamento urbano, transportes e mobilidade com qualificação superior, do total de trabalhadores destes órgãos no ano de referência.

Escore: $8 \%$

Normalização: 0,15

Estágios:

\begin{tabular}{|c|l|}
\hline Escore & $\begin{array}{l}\text { Valores de Referência } \\
\text { Porcentagem dos técnicos e gestores de órgãos de planejamento } \\
\text { urbano, transportes e mobilidade, no ano de referência, que } \\
\text { possuem qualificação superior }\end{array}$ \\
\hline 1,00 & $25 \%$ ou mais \\
\hline 0,75 & $20 \%$ \\
\hline 0,50 & $15 \%$ \\
\hline 0,25 & $10 \%$ \\
\hline 0,00 & Até $5 \%$ \\
\hline
\end{tabular}

\section{SIMULACÃO AMBICIOSA:}

Variação de Estágio: 1,75 x 5\% = 8,75\%

Escore a ser atingido: $8 \%+8,75=16,75 \%$

Valor normalizado: 0,59

Ação consequente: Possuir dentre o corpo técnico da Secretaria Municipal de Transporte e Trânsito, pelo menos 17 dos 100 funcionários com qualificação superior.

\section{SIMULACÃO CONSERVADORA:}

Variação de Estágio: $0,75 \times 5 \%=3,75 \%$

Escore a ser atingido: $8 \%+3,75 \%=12 \%$

Valor normalizado: 0,35

Ação consequente: Possuir dentre o corpo técnico da Secretaria Municipal de Transporte e Trânsito, pelo menos 12 dos 100 funcionários com qualificação superior. 


\begin{tabular}{|l|l|}
\hline DOMÍNIO & Planejamento Integrado \\
\hline TEMA & Capacitação de gestores \\
\hline INDICADOR 7.1.2 & Capacitação de técnicos e gestores \\
\hline
\end{tabular}

Definição: Número de horas de treinamento e capacitação oferecidas por técnico e gestor das áreas de planejamento urbano, transportes e mobilidade durante $o$ ano de referência.

Escore: 16 horas/funcionário/ano

Normalização: 0,25

Estágios:

\begin{tabular}{|c|l|}
\hline Escore & $\begin{array}{l}\text { Valores de Referência } \\
\text { Horas/funcionário/ano de cursos e treinamentos oferecidos a } \\
\text { técnicos e gestores das áreas de planejamento urbano, transportes } \\
\text { e mobilidade no ano de referência }\end{array}$ \\
\hline 1,00 & 40 horas ou mais \\
\hline 0,75 & 32 horas \\
\hline 0,50 & 24 horas \\
\hline 0,25 & 16 horas \\
\hline 0,00 & 8 horas ou menos \\
\hline
\end{tabular}

\section{SIMULACÃO AMBICIOSA:}

Variação de Estágio: $1,5 \times 8 \mathrm{~h}=12 \mathrm{~h}$

Escore a ser atingido: $16+12=28$ horas/func./ano

Valor normalizado: 0,63

Ação consequente: Aumentar a carga horária de cursos e treinamentos de 16 para 28 horas/funcionário/ano, ou, oferecer cursos de pelo menos 2,5 horas mensais para todos os funcionários.

\section{SIMULACÃO CONSERVADORA:}

Variação de Estágio: $0,5 \times 8 \mathrm{~h}=4 \mathrm{~h}$

Escore a ser atingido: $16+4=20$ horas/func./ano

Valor normalizado: 0,38 
Ação consequente: Aumentar a carga horária de cursos e treinamentos de 16 para 20 horas/funcionário/ano, ou, oferecer cursos de pelo menos 1 hora e 40 minutos mensais para todos os funcionários. 


\begin{tabular}{|l|l|}
\hline DOMÍNIO & Planejamento Integrado \\
\hline TEMA & Áreas centrais e de interesse histórico \\
\hline INDICADOR 7.2.1 & Vitalidade do centro \\
\hline
\end{tabular}

Definição: Medida da vitalidade do centro da cidade em dois momentos distintos, baseada no número de residentes e no número de empregos nos setores de comércio e serviços localizados na área.

Escore: 0,83

Normalização: 0,42

\section{Estágios:}

\begin{tabular}{|c|l|}
\hline Escore & Valores de Referência \\
\hline 1,00 & $\begin{array}{l}\text { I }>1,50 \text { O centro apresenta forte tendência de crescimento do } \\
\text { número de domicílios particulares e empregos nos setores de } \\
\text { comércio e serviços, e forte equilíbrio entre as atividades diurnas } \\
\text { e noturnas }\end{array}$ \\
\hline 0,75 & $\begin{array}{l}\text { I=1,50 O centro apresenta tendência de crescimento do número } \\
\text { de domicílios particulares e empregos nos setores de comércio e } \\
\text { serviços, e equilíbrio entre as atividades diurnas e noturnas }\end{array}$ \\
\hline 0,50 & $\begin{array}{l}\text { I=1,00 O centro apresenta tendência de estabilidade com } \\
\text { manutenção do número de domicílios particulares e empregos } \\
\text { nos setores de comércio e serviços, e equilíbrio entre as } \\
\text { atividades diurnas e noturnas }\end{array}$ \\
\hline 0,25 & $\begin{array}{l}\text { I=0,50 O centro da cidade apresenta tendência de } \\
\text { esvaziamento, com declínio do número de domicílios particulares } \\
\text { e empregos nos setores de comércio e serviços, e desequilíbrio } \\
\text { entre as atividades diurnas e noturnas }\end{array}$ \\
$\begin{array}{l}\text { I<0,50 O centro da cidade apresenta forte tendência de } \\
\text { esvaziamento, com declínio acentuado do número de domicílios } \\
\text { particulares e empregos nos setores de comércio e serviços, e } \\
\text { forte desequilíbrio entre as atividades diurnas e noturnas }\end{array}$ \\
\hline
\end{tabular}

\section{SIMULAČ̃A AMBICIOSA:}

Variação de Estágio: $1,5 \times 0,5=0,75$

Escore a ser atingido: $0,83+0,75=1,58$ (aproximou-se de 1,5)

Valor normalizado: 0,75

Ação consequente: $O$ número de domicílios e empregos na área central deve apresentar um crescimento de até $50 \%$ em cinco anos e manter equilibrio entre atividades diurnas e noturnas. 


\section{SIMULACÃO CONSERVADORA:}

Variação de Estágio: $0,25 \times 0,5=0,125$

Escore a ser atingido: $0,83+0,125=0,96$

Valor normalizado: 0,48

Ação consequente: $O$ número de domicílios e empregos na área central deve

permanecer estabilizado em cinco anos e manter equilibrio entre atividades diurnas e noturnas. 


\begin{tabular}{|l|l|}
\hline DOMÍNIO & Planejamento Integrado \\
\hline TEMA & Integração regional \\
\hline INDICADOR 7.3.1 & Consórcios intermunicipais \\
\hline
\end{tabular}

Definição: Existência de consórcios públicos intermunicipais para provisão de infraestrutura e serviços de transportes urbano e metropolitano.

Escore: Não foi firmado ou encontra-se em vigor nenhum consórcio intermunicipal para provisão de infraestrutura e prestação de serviços de transporte.

Normalização: 0,00

Estágios:

\begin{tabular}{|c|l|}
\hline Escore & $\begin{array}{l}\text { Valores de Referência } \\
\text { Foi firmado ou encontra-se em vigor no ano de referência consórcio } \\
\text { intermunicipal para: }\end{array}$ \\
\hline 1,00 & $\begin{array}{l}\text { Aquisição de máquinas e equipamentos, execução de obras de } \\
\text { manutenção, conservação e construção de infraestrutura e } \\
\text { prestação de serviços de transporte urbano e metropolitano }\end{array}$ \\
\hline 0,75 & $\begin{array}{l}\text { Aquisição de máquinas e equipamentos e execução de obras de } \\
\text { manutenção, conservação e construção de infraestrutura de } \\
\text { transportes }\end{array}$ \\
\hline 0,50 & $\begin{array}{l}\text { Aquisição de máquinas e equipamentos e execução de obras de } \\
\text { manutenção e conservação de infraestrutura de transportes }\end{array}$ \\
\hline 0,25 & $\begin{array}{l}\text { Aquisição de máquinas e equipamentos para provisão de } \\
\text { infraestrutura de transportes }\end{array}$ \\
\hline $\begin{array}{l}\text { Não foi firmado ou encontra-se em vigor nenhum consórcio } \\
\text { intermunicipal para provisão de infraestrutura e prestação de } \\
\text { serviços de transporte }\end{array}$ \\
\hline
\end{tabular}

\section{SIMULACCÃO AMBICIOSA:}

Variação de Estágio: $1,5 \times 0,25=0,375$

Escore a ser atingido: $0,00+0,375=0,375$ (por ser quantitativo aproximou-se de 0,50)

Valor normalizado: 0,50

Ação consequente: Firmar consórcio intermunicipal para a aquisição de máquinas e equipamentos e execução de obras de manutenção, conservação e construção de infraestrutura de transportes. 


\section{SIMULACÃO CONSERVADORA:}

Variação de Estágio: $0,5 \times 0,25=0,125$

Escore a ser atingido: $0,00+0,125=0,125$ (Por ser qualitativo, aproximou-se de 0,25 )

Valor normalizado: 0,25

Ação consequente: Firmar consórcio intermunicipal para a aquisição de máquinas e equipamentos para provisão de infraestrutura de transportes. 


\begin{tabular}{|l|l|}
\hline DOMÍNIO & Planejamento Integrado \\
\hline TEMA & Transparência do processo de planejamento \\
\hline INDICADOR 7.4.1 & Transparência e responsabilidade \\
\hline
\end{tabular}

Definição: Existência de publicação formal e periódica por parte da administração municipal sobre assuntos relacionados à infraestrutura, serviços, planos e projetos de transportes e mobilidade urbana.

Escore: Contratos e licitações para execução de obras de infraestrutura e prestação de serviços de transporte público, estágio de desenvolvimento de planos e projetos e aplicação e fonte de recursos para planos e projetos de transportes e mobilidade urbana.

Normalização: 0,75

\section{Estágios:}

\begin{tabular}{|c|l|}
\hline Escore & $\begin{array}{l}\text { Valores de Referência } \\
\text { Existência de publicação formal e periódica sobre: }\end{array}$ \\
\hline 1,00 & $\begin{array}{l}\text { Contratos e licitações para execução de obras de infraestrutura e } \\
\text { prestação de serviços de transporte público, estágio de } \\
\text { desenvolvimento de planos e projetos, aplicação e fonte de } \\
\text { recursos, e impactos sociais, econômicos e ambientais de planos e } \\
\text { projetos de transportes e mobilidade urbana }\end{array}$ \\
\hline 0,75 & $\begin{array}{l}\text { Contratos e licitações para execução de obras de infraestrutura e } \\
\text { prestação de serviços de transporte público, estágio de } \\
\text { desenvolvimento de planos e projetos e aplicação e fonte de } \\
\text { recursos para planos e projetos de transportes e mobilidade urbana }\end{array}$ \\
\hline 0,50 & $\begin{array}{l}\text { Contratos e licitações para execução de obras de infraestrutura e } \\
\text { prestação de serviços de transporte público, e estágio de } \\
\text { desenvolvimento de planos e projetos de transportes e mobilidade } \\
\text { urbana }\end{array}$ \\
\hline 0,25 & $\begin{array}{l}\text { Contratos e licitações para execução de obras de infraestrutura e } \\
\text { prestação de serviços de transporte públicos }\end{array}$ \\
\hline 0,00 & $\begin{array}{l}\text { Não há publicação formal e periódica sobre assuntos relacionados } \\
\text { à infraestrutura, serviços, planos e projetos de transportes e } \\
\text { mobilidade urbana }\end{array}$ \\
\hline
\end{tabular}

\section{SIMULACÃO AMBICIOSA:}

Variação de Estágio: $2 \times 0,25=0,50$

Escore a ser atingido: $0,75+0,50=1,00$ (excede o valor máximo)

Valor normalizado: 1,00 
Ação consequente: Divulgar nas publicações formais periódicas informações referentes à aplicação e fonte de recursos, impactos sociais, econômicos e ambientais de planos e projetos de transportes e mobilidade urbana.

\section{SIMULACÃO CONSERVADORA:}

Variação de Estágio: 1 x 0,25 =0,25

Escore a ser atingido: $0,75+0,25=1,00$

Valor normalizado: 1,00

Ação consequente: Divulgar nas publicações formais periódicas informações referentes à aplicação e fonte de recursos, impactos sociais, econômicos e ambientais de planos e projetos de transportes e mobilidade urbana. 


\begin{tabular}{|l|l|}
\hline DOMÍNIO & Planejamento Integrado \\
\hline TEMA & Planejamento e controle do uso e ocupação do solo \\
\hline INDICADOR 7.5.1 & Vazios urbanos \\
\hline
\end{tabular}

Definição: Porcentagem de áreas que se encontram vazias ou desocupadas na área urbana do município.

Escore: 19,93\%

Normalização: 0,75

Estágios:

\begin{tabular}{|c|l|}
\hline Escore & $\begin{array}{l}\text { Valores de Referência } \\
\text { Porcentagem da área urbana do município vazia ou desocupada. }\end{array}$ \\
\hline 1,00 & Até $10 \%$ \\
\hline 0,75 & $20 \%$ \\
\hline 0,50 & $30 \%$ \\
\hline 0,25 & $40 \%$ \\
\hline 0,00 & $50 \%$ ou mais \\
\hline
\end{tabular}

\section{SIMULACÃO AMBICIOSA:}

Variação de Estágio: $0,5 \times-10 \%=-5 \%$

Escore a ser atingido: $19,93 \%-5 \%=14,93 \%$

Valor normalizado: 0,88

Ação consequente: Reduzir em $3,36 \mathrm{~km}^{2}$ (do total de $67,25 \mathrm{~km}^{2}$ do município)

a área de vazios no tecido urbano ${ }^{11}$.

\section{SIMULAÇÃO CONSERVADORA:}

Variação de Estágio: Não há.

Escore a ser atingido: -

Valor normalizado: 0,75

Ação consequente: Manter estabilizada a área de vazios no tecido urbano.

\footnotetext{
${ }^{11}$ A atual área de vazios é de $26,3 \mathrm{~km}^{2}$.
} 


\begin{tabular}{|l|l|}
\hline DOMÍNIO & Planejamento Integrado \\
\hline TEMA & Planejamento e controle do uso e ocupação do solo \\
\hline INDICADOR 7.5.2 & Crescimento urbano \\
\hline
\end{tabular}

Definição: Razão entre a área de novos projetos (para diferentes usos) previstos ou em fase de implantação em regiões dotadas de infraestrutura e serviços de transportes, e a área de novos projetos em regiões ainda não desenvolvidas e sem infraestrutura de transportes.

Escore: 1,21

Normalização: 0,61

Estágios:

\begin{tabular}{|c|l|}
\hline Escore & $\begin{array}{l}\text { Valores de Referência } \\
\text { Razão entre a área total de novos projetos em áreas dotadas de } \\
\text { infraestrutura de transportes e a área total de novos projetos em } \\
\text { áreas sem infraestrutura de transportes }\end{array}$ \\
\hline 1,00 & lgual ou maior que 2 \\
\hline 0,75 & 1,5 \\
\hline 0,50 & 1 \\
\hline 0,25 & 0,5 \\
\hline 0,00 & 0 \\
\hline
\end{tabular}

\section{SIMULACÃO AMBICIOSA:}

Variação de Estágio: Não há.

Escore a ser atingido: -

Valor normalizado: 0,61

Ação consequente: Manter estabilizada a área do município.

\section{SIMULAC̄ÃO CONSERVADORA:}

Variação de Estágio: Não há.

Escore a ser atingido: -

Valor normalizado: 0,61

Ação consequente: Manter estabilizada a área do município. 


\begin{tabular}{|l|l|}
\hline DOMÍNIO & Planejamento Integrado \\
\hline TEMA & Planejamento e controle do uso e ocupação do solo \\
\hline INDICADOR 7.5.3 & Densidade populacional urbana \\
\hline
\end{tabular}

Definição: Razão entre o número total de habitantes da área urbana e a área total urbanizada do município.

Escore: 2.684 habitantes $/ \mathrm{km}^{2}$

Normalização: 0,00

\section{Estágios:}

\begin{tabular}{|c|c|}
\hline Escore & $\begin{array}{l}\text { Valores de Referência } \\
\text { Densidade populacional urbana }\end{array}$ \\
\hline 1,00 & 45.000 habitantes $/ \mathrm{km}^{2}$ ou 450 habitantes $/$ ha \\
\hline 0,75 & 35.000 habitantes $/ \mathrm{km}^{2}$ ou 350 habitantes $/$ ha \\
\hline 0,50 & 25.000 habitantes $/ \mathrm{km}^{2}$ ou 250 habitantes $/$ ha \\
\hline 0,25 & 15.000 habitantes $/ \mathrm{km}^{2}$ ou 150 habitantes/ha \\
\hline 0,00 & $\begin{array}{l}\text { Até } 5.000 \text { habitantes } / \mathrm{km}^{2} \text { ou } 50 \text { habitantes } / \text { ha ou superior a } \\
45.00 \text { habitantes } / \mathrm{km}^{2} \text { ou } 450 \text { habitantes/ha }\end{array}$ \\
\hline
\end{tabular}

\section{SIMULAÇÃO AMBICIOSA:}

Variação de Estágio: 0,5 x $10000=5000$ hab. $/ \mathrm{km}^{2}$

Escore a ser atingido: $2.684+5000=7.684 \mathrm{hab} . / \mathrm{km}^{2}$

Valor normalizado: 0,07

Ação consequente: Incentivar o adensamento populacional na área urbana atual para que haja um aumento de 5.000 habitantes por $\mathrm{km}^{2}$.

\section{SIMULACÃO CONSERVADORA:}

Variação de Estágio: Não há.

Escore a ser atingido: -

Valor normalizado: 0,00

Ação consequente: - 


\begin{tabular}{|l|l|}
\hline DOMÍNIO & Planejamento Integrado \\
\hline TEMA & Planejamento e controle do uso e ocupação do solo \\
\hline INDICADOR 7.5.4 & Índice de uso misto \\
\hline
\end{tabular}

Definição: Porcentagem da área urbana destinada ao uso misto do solo, conforme definido em legislação municipal.

Escore: 90,93\%

Normalização: 1,00

Estágios:

\begin{tabular}{|c|l|}
\hline Escore & $\begin{array}{l}\text { Valores de Referência } \\
\text { Porcentagem da área urbana do município onde é } \\
\text { permitido/incentivado o uso misto do solo com atividades } \\
\text { compatíveis entre si e com o uso residencial }\end{array}$ \\
\hline 1,00 & Mais de 75\% \\
\hline 0,75 & $75 \%$ \\
\hline 0,50 & $50 \%$ \\
\hline 0,25 & $25 \%$ \\
0,00 & $\begin{array}{l}\text { A legislação urbanística municipal não permite o uso misto do solo, } \\
\text { determinando zonas de uso exclusivamente residencial, comercial, } \\
\text { industrial ou institucional, resultando em intensa setorização da } \\
\text { área urbana }\end{array}$ \\
\hline
\end{tabular}

\section{SIMULACÃO AMBICIOSA:}

Variação de Estágio: 1,75

Escore a ser atingido: Está no máximo.

Valor normalizado: 1,00

Ação consequente: Manter o incentivo ao uso misto do solo.

\section{SIMULAC̄ÃO CONSERVADORA:}

Variação de Estágio: 0,75

Escore a ser atingido: Está no máximo.

Valor normalizado: 1,00

Ação consequente: Manter o incentivo ao uso misto do solo. 


\begin{tabular}{|l|l|}
\hline DOMÍNIO & Planejamento Integrado \\
\hline TEMA & Planejamento e controle do uso e ocupação do solo \\
\hline INDICADOR 7.5.5 & Ocupação irregulares \\
\hline
\end{tabular}

Definição: Porcentagem da área urbana constituída por assentamentos informais ou irregulares.

Escore: 0,05\%

Normalização: 1,00

Estágios:

\begin{tabular}{|c|l|}
\hline Escore & $\begin{array}{l}\text { Valores de Referência } \\
\text { Porcentagem da área urbana constituída de ocupações irregulares } \\
\text { e assentamentos informais }\end{array}$ \\
\hline 1,00 & Até $5 \%$ \\
\hline 0,75 & $10 \%$ \\
\hline 0,50 & $15 \%$ \\
\hline 0,25 & $20 \%$ \\
\hline 0,00 & Mais de $20 \%$ \\
\hline
\end{tabular}

\section{SIMULAÇÃO AMBICIOSA:}

Variação de Estágio: 1,5

Escore a ser atingido: Está no máximo.

Valor normalizado: 1,00

Ação consequente: Manter a fiscalização para que os loteamentos irregulares permaneçam abaixo dos $5 \%$ do total da área urbana.

\section{SIMULACÃO CONSERVADORA:}

Variação de Estágio: 0,25

Escore a ser atingido: Está no máximo.

Valor normalizado: 1,00

Ação consequente: Manter a fiscalização para que os loteamentos irregulares permaneçam abaixo dos $5 \%$ do total da área urbana. 


\begin{tabular}{|l|l|}
\hline DOMÍNIO & Planejamento Integrado \\
\hline TEMA & Planejamento estratégico e integrado \\
\hline INDICADOR 7.6.1 & $\begin{array}{l}\text { Planejamento urbano, ambiental e de transportes } \\
\text { integrado }\end{array}$ \\
\hline
\end{tabular}

Definição: Existência de cooperação formalizada entre os órgãos responsáveis pelo planejamento e gestão de transportes, planejamento urbano e meio ambiente no desenvolvimento de estratégias integradas para a melhoria das condições de mobilidade urbana.

Escore: Órgãos gestores de transportes, meio ambiente e planejamento urbano no desenvolvimento de ações pontuais para melhoria das condições de mobilidade urbana.

Normalização: 0,50

\section{Estágios:}

\begin{tabular}{|c|l|}
\hline Escore & $\begin{array}{l}\text { Valores de Referência } \\
\text { Há cooperação formal entre: }\end{array}$ \\
\hline 1,00 & $\begin{array}{l}\text { Órgãos gestores de transportes, meio ambiente e planejamento } \\
\text { urbano no desenvolvimento de planos e programas de } \\
\text { abrangência municipal para melhoria das condições de mobilidade } \\
\text { urbana, inclusive com a instituição de um órgão intersecretarial } \\
\text { permanente }\end{array}$ \\
\hline 0,75 & $\begin{array}{l}\text { Órgãos gestores de transportes, meio ambiente e planejamento } \\
\text { urbano no desenvolvimento de planos e programas de } \\
\text { abrangência municipal para melhoria das condições de mobilidade } \\
\text { urbana ana }\end{array}$ \\
\hline 0,50 & $\begin{array}{l}\text { Órgãos gestores de transportes, meio ambiente e planejamento } \\
\text { urbano no desenvolvimento de ações pontuais para melhoria das } \\
\text { condições de mobilidade urbana }\end{array}$ \\
\hline 0,25 & $\begin{array}{l}\text { Órgãos gestores de transportes, meio ambiente e planejamento } \\
\text { urbano no desenvolvimento de ações pontuais para melhoria das } \\
\text { condições de mobilidade urbana }\end{array}$ \\
\hline \multirow{2}{*}{0,00} & $\begin{array}{l}\text { Não há qualquer forma de cooperação entre os órgãos gestores de } \\
\text { desenvolvimento de planos e ações para melhoria das condições } \\
\text { de mobilidade urbana }\end{array}$ \\
\hline
\end{tabular}

SIMULACÃO AMBICIOSA:

Variação de Estágio: 0,5 × 0,25 = 0,125 
Escore a ser atingido: $0,50+0,125=0,625$ (por ser qualitativo, aproxima-se de 0,75 )

\section{Valor normalizado: 0,75}

Ação consequente: Desenvolver planos e programas de abrangência municipal resultado de cooperação entre órgãos gestores de transportes, meio ambiente e planejamento urbano para melhoria das condições de mobilidade urbana.

\section{SIMULACÃO CONSERVADORA:}

Variação de Estágio: Não há

Escore a ser atingido: -

Valor normalizado: 0,50

Ação consequente: Manter a cooperação entre órgaos gestores de transportes, meio ambiente e planejamento urbano no desenvolvimento de ações para melhoria das condições de mobilidade urbana. 


\begin{tabular}{|l|l|}
\hline DOMÍNIO & Planejamento Integrado \\
\hline TEMA & Planejamento estratégico e integrado \\
\hline INDICADOR 7.6.2 & Efetivação e continuidade das ações \\
\hline
\end{tabular}

Definição: Programas e projetos de transportes e mobilidade urbana efetivados pela administração municipal no ano de referência e continuidade das ações implementadas.

Observação: $A$ insuficiência de dados impossibilitou a execução do cálculo deste indicador. Algumas ações para transportes e mobilidade urbana previstas pela atual gestão devem ser efetivadas e mantidas pelas próxima gestão. Nos cenários também não foram calculados para evitar a redistribuição dos pesos entre os indicadores.

\section{Escore: -}

\section{Normalização: -}

\section{Estágios:}

\begin{tabular}{|c|l|}
\hline Escore & Valores de Referência \\
\hline 1,00 & $\begin{array}{l}\text { Grande parte das ações para transportes e mobilidade urbana } \\
\text { previstas pela atual gestão foram efetivadas, tendo sido dada } \\
\text { continuidade às mesmas mesmo após mudanças no quadro da } \\
\text { administração municipal }\end{array}$ \\
\hline 0,75 & $\begin{array}{l}\text { Algumas ações para transportes e mobilidade urbana previstas } \\
\text { pela atual gestão foram efetivadas, tendo sido dada continuidade } \\
\text { às mesmas mesmo após mudanças no quadro da administração } \\
\text { municipal }\end{array}$ \\
\hline 0,50 & $\begin{array}{l}\text { Grande parte das ações para transportes e mobilidade urbana } \\
\text { previstas pela atual gestão foi efetivada, no entanto, grande parte } \\
\text { foi abandonada em função de mudanças no quadro da } \\
\text { administração municipal }\end{array}$ \\
\hline 0,25 & $\begin{array}{l}\text { Algumas ações para transportes e mobilidade urbana previstas } \\
\text { pela atual gestão foram efetivadas, no entanto, grande parte foi } \\
\text { abandonada em função de mudanças no quadro da administração } \\
\text { municipal }\end{array}$ \\
\hline 0,00 & $\begin{array}{l}\text { Nenhuma ação para transportes e mobilidade urbana prevista pela } \\
\text { atual gestão não foi efetivada }\end{array}$ \\
\hline
\end{tabular}


SIMULACÃO AMBICIOSA:

Variação de Estágio: 1

Escore a ser atingido:

Valor normalizado: -

Ação consequente:

SIMULAC̄̃̃O CONSERVADORA:

Variação de Estágio: 0,1

Escore a ser atingido: -

Valor normalizado: -

Ação consequente: - 


\begin{tabular}{|l|l|}
\hline DOMINIO & Planejamento Integrado \\
\hline TEMA & $\begin{array}{l}\text { Planejamento da infraestrutura urbana e equipamentos } \\
\text { urbanos }\end{array}$ \\
\hline INDICADOR 7.7.1 & Parques e áreas verdes \\
\hline
\end{tabular}

Definição: Área urbana com cobertura vegetal (parques, jardins, áreas verdes) por habitante.

Escore: $20,85 \mathrm{~m}^{2} /$ habitante

Normalização: 0,79

Estágios:

\begin{tabular}{|c|l|}
\hline Escore & $\begin{array}{l}\text { Valores de Referência } \\
\text { Área verde por habitante }\end{array}$ \\
\hline 1,00 & Igual ou superior a $25 \mathrm{~m}^{2}$ por habitante \\
\hline 0,75 & $20 \mathrm{~m}^{2}$ por habitante \\
\hline 0,50 & $15 \mathrm{~m}^{2}$ por habitante \\
\hline 0,25 & $10 \mathrm{~m}^{2}$ por habitante \\
\hline 0,00 & Igual ou inferior a $5 \mathrm{~m}^{2}$ por habitante \\
\hline
\end{tabular}

\section{SIMULACÃO AMBICIOSA:}

Variação de Estágio: $1,5 \times 5=7,5 \mathrm{~m}^{2} / \mathrm{hab}$

Escore a ser atingido: $20,85+7,5=28,35 \mathrm{~m}^{2} / \mathrm{hab}$

Valor normalizado: 1,00

Ação consequente: Implantar no mínimo $1,35 \mathrm{~km}^{2}\left(1.353 .675 \mathrm{~m}^{2}\right)$ de área verde além da existente ${ }^{12}$.

\section{SIMULACÃO CONSERVADORA:}

Variação de Estágio: $0,5 \times 5=2,5 \mathrm{~m}^{2} / \mathrm{hab}$

Escore a ser atingido: $20,85+2,5=23,35 \mathrm{~m}^{2} / \mathrm{hab}$

Valor normalizado: 0,92

Ação consequente: Implantar no mínimo $451.225 \mathrm{~m}^{2}$ de área verde além da existente ${ }^{12}$.

${ }^{12}$ População do censo 2000 do IBGE e mapas de 2008. 


\begin{tabular}{|l|l|}
\hline DOMINIO & Planejamento Integrado \\
\hline TEMA & $\begin{array}{l}\text { Planejamento da infraestrutura urbana e equipamentos } \\
\text { urbanos }\end{array}$ \\
\hline INDICADOR 7.7.2 & Equipamentos urbanos (escolas) \\
\hline
\end{tabular}

Definição: Número de escolas em nível de educação infantil e ensino fundamental, públicas e particulares, por 1000 habitantes.

Escore: 0,41 escolas/1.000 habitantes

Normalização: 0,16

Estágios:

\begin{tabular}{|c|l|}
\hline Escore & $\begin{array}{l}\text { Valores de Referência } \\
\text { Número de escolas por } 1000 \text { habitantes no município }\end{array}$ \\
\hline 1,00 & Igual ou superior a 1,25 \\
\hline 0,75 & 1,00 \\
\hline 0,50 & 0,75 \\
\hline 0,25 & 0,50 \\
\hline 0,00 & Igual ou inferior a 0,25 \\
\hline
\end{tabular}

\section{SIMULACÃO AMBICIOSA:}

Variação de Estágio: 1,25 x 0,25 =0,3125 escolas/1000 hab.

Escore a ser atingido: $0,41+0,3125=0,72$ escolas $/ 1000$ hab.

Valor normalizado: 0,47

Ação consequente: Construir 67 escolas em nível de educação infantil e ensino fundamental, públicas e particulares ${ }^{13}$.

\section{SIMULAÇÃO CONSERVADORA:}

Variação de Estágio: $0,1 \times 0,25=0,025$ escolas $/ 1000$ hab.

Escore a ser atingido: $0,41+0,025=0,44$ escolas $/ 1000$ hab.

Valor normalizado: 0,19

Ação consequente: Construir 7 escolas em nível de educação infantil e ensino fundamental, públicas e particulares.

\footnotetext{
${ }^{13}$ População estimada pelo Censo 2007 do IBGE.
} 


\begin{tabular}{|l|l|}
\hline DOMINIO & Planejamento Integrado \\
\hline TEMA & $\begin{array}{l}\text { Planejamento da infraestrutura urbana e equipamentos } \\
\text { urbanos }\end{array}$ \\
\hline INDICADOR 7.7.3 & Equipamentos urbanos (postos de saúde) \\
\hline
\end{tabular}

Definição: Número de equipamentos de saúde ou unidades de atendimento médico primário (postos de saúde) por 100.000 habitantes.

Escore: 13,14 postos de saúde/100.000 habitantes

Normalização: 0,08

Estágios:

\begin{tabular}{|c|l|}
\hline Escore & $\begin{array}{l}\text { Valores de Referência } \\
\text { Número de postos de saúde por } 100.000 \text { habitantes no município }\end{array}$ \\
\hline 1,00 & 50 ou mais \\
\hline 0,75 & 40 \\
\hline 0,50 & 30 \\
\hline 0,25 & 20 \\
\hline 0,00 & Até 10 \\
\hline
\end{tabular}

\section{SIMULACÃO AMBICIOSA:}

Variação de Estágio: 1,25 x $10=12,5$ postos de saúde/100.000 habitantes

Escore a ser atingido: $13,14+12,5=25,90$ postos de saúde/100.000 hab.

Valor normalizado: 0,40

Ação consequente: Construir 27 equipamentos de saúde ou unidades de atendimento médico primário (postos de saúde) $)^{14}$.

\section{SIMULAÇÃO CONSERVADORA:}

Variação de Estágio: $0,1 \times 10=1$ posto de saúde/100.000 hab.

Escore a ser atingido: $13,14+1=14,14$ postos de saúde/100.000 hab.

Valor normalizado: 0,10

Ação consequente: Construir 2 equipamentos de saúde ou unidades de atendimento médico primário (postos de saúde) $)^{14}$.

\footnotetext{
${ }^{14}$ População estimada pelo Censo 2007 do IBGE.
} 


\begin{tabular}{|l|l|}
\hline DOMÍNIO & Planejamento Integrado \\
\hline TEMA & Plano Diretor e legislação urbanística \\
\hline INDICADOR 7.8.1 & Plano Diretor \\
\hline
\end{tabular}

Definição: Existência e ano de elaboração/atualização do Plano Diretor Municipal.

Escore: O município dispõe de Plano Diretor, implantado ou atualizado há menos de 7 anos.

Normalização: 1,00

Estágios:

\begin{tabular}{|c|l|}
\hline Escore & $\begin{array}{l}\text { Valores de Referência } \\
\text { O município dispõe de Plano Diretor, implantado ou atualizado há: }\end{array}$ \\
\hline 1,00 & Menos de 7 anos \\
\hline 0,50 & Mais de 7 anos \\
\hline 0,00 & O município não dispõe de Plano Diretor \\
\hline
\end{tabular}

\section{SIMULACÃO AMBICIOSA:}

Variação de Estágio: 1,75

Escore a ser atingido: Está no máximo.

Valor normalizado: 1,00

Ação consequente: Manter o Plano Diretor Municipal atualizado em menos de 7 anos.

\section{SIMULAC̄ÃO CONSERVADORA:}

Variação de Estágio: 0,75

Escore a ser atingido: Está no máximo.

Valor normalizado: 1,00

Ação consequente: Manter o Plano Diretor Municipal atualizado em menos de 7 anos. 
\begin{tabular}{|l|l|}
\hline DOMÍNIO & Planejamento Integrado \\
\hline
\end{tabular}

TEMA $\quad$ Plano Diretor e legislação urbanística

INDICADOR 7.8.2 Legislação urbanística

Definição: Existência de legislação urbanística.

Escore: Lei do Perímetro Urbano, Lei de Zoneamento ou equivalente, Lei de Uso e Ocupação do Solo, Código de Obras, Código de Posturas, Legislação Sobre Áreas de Interesse Especial

Normalização: 0,6 
Estágios:

\begin{tabular}{|c|c|}
\hline Escore & $\begin{array}{l}\text { Valores de Referência } \\
\text { O município dispõe dos seguintes instrumentos: }\end{array}$ \\
\hline 1,00 & $\begin{array}{l}\text { Lei do Perímetro Urbano, Lei de Zoneamento ou equivalente, Lei } \\
\text { de Uso e Ocupação do Solo, Código de Obras, Código de } \\
\text { Posturas, Legislação Sobre Áreas de Interesse Especial, } \\
\text { Legislação de Interesse Social, instrumentos para o Parcelamento, } \\
\text { Edificação ou Utilização Compulsórios, Outorga Onerosa do Direito } \\
\text { de Construir, Operações Urbanas Consorciadas ou outros } \\
\text { instrumentos de planejamento urbano }\end{array}$ \\
\hline 0,90 & $\begin{array}{l}\text { Lei do Perímetro Urbano, Lei de Zoneamento ou equivalente, Lei } \\
\text { de Uso e Ocupação do Solo, Código de Obras, Código de } \\
\text { Posturas, Legislação Sobre Áreas de Interesse Especial, } \\
\text { Legislação de Interesse Social, instrumentos para o Parcelamento, } \\
\text { Edificação ou Utilização Compulsórios e Outorga Onerosa do } \\
\text { Direito de Construir }\end{array}$ \\
\hline 0,80 & $\begin{array}{l}\text { Lei do Perímetro Urbano, Lei de Zoneamento ou equivalente, Lei } \\
\text { de Uso e Ocupação do Solo, Código de Obras, Código de } \\
\text { Posturas, Legislação Sobre Áreas de Interesse Especial, } \\
\text { Legislação de Interesse Social, instrumento para o Parcelamento, } \\
\text { Edificação ou Utilização Compulsórios }\end{array}$ \\
\hline 0,70 & $\begin{array}{l}\text { Lei do Perímetro Urbano, Lei de Zoneamento ou equivalente, Lei } \\
\text { de Uso e Ocupação do Solo, Código de Obras, Código de } \\
\text { Posturas, Legislação Sobre Áreas de Interesse Especial, } \\
\text { Legislação de Interesse Social }\end{array}$ \\
\hline 0,60 & $\begin{array}{l}\text { Lei do Perímetro Urbano, Lei de Zoneamento ou equivalente, Lei } \\
\text { de Uso e Ocupação do Solo, Código de Obras, Código de } \\
\text { Posturas, Legislação Sobre Áreas de Interesse Especial }\end{array}$ \\
\hline 0,50 & $\begin{array}{l}\text { Lei do Perímetro Urbano, Lei de Zoneamento ou equivalente, Lei } \\
\text { de Uso e Ocupação do Solo, Código de Obras, Código de } \\
\text { Posturas }\end{array}$ \\
\hline 0,40 & $\begin{array}{l}\text { Lei do Perímetro Urbano, Lei de Zoneamento ou equivalente, Lei } \\
\text { de Uso e Ocupação do Solo, Código de Obras }\end{array}$ \\
\hline 0,30 & $\begin{array}{l}\text { Lei do Perímetro Urbano, Lei de Zoneamento ou equivalente, Lei } \\
\text { de Uso e Ocupação do Solo }\end{array}$ \\
\hline 0,20 & Lei do Perímetro Urbano, Lei de Zoneamento ou equivalente \\
\hline & Lei do Perímetro Urbano \\
\hline 0,00 & o não dispõe de legislação urbanística \\
\hline
\end{tabular}

SIMULAC̣ÃO AMBICIOSA:

Variação de Estágio: $1,5 \times 0,10=0,15$

Escore a ser atingido: $0,6+0,15=0,75$

Valor normalizado: 0,75 
Ação consequente: Implantar na legislação municipal no mínimo os instrumentos: Legislação de Interesse Social e instrumentos para o Parcelamento, Edificação ou Utilização Compulsórios.

\section{SIMULACÃO CONSERVADORA:}

Variação de Estágio: $0,5 \times 0,10=0,05$

Escore a ser atingido: $0,60+0,05=0,65$ (por ser qualitativo, aproximou-se de $0,70)$

Valor normalizado: 0,70

Ação consequente: Implantar na legislação municipal no mínimo uma Legislação de Interesse Social. 


\begin{tabular}{|l|l|}
\hline DOMÍNIO & Planejamento Integrado \\
\hline TEMA & Plano Diretor e legislação urbanística \\
\hline INDICADOR 7.8.3 & Cumprimento da legislação urbanística \\
\hline
\end{tabular}

Definição: Fiscalização por parte da administração municipal com relação ao cumprimento da legislação urbanística vigente.

Escore: A administração municipal tem realizado operações de fiscalização de obras e empreendimentos em desacordo com a legislação urbanística municipal, notificação e autuação dos responsáveis, incluindo aplicação de multas.

Normalização: 0,75

Estágios:

\begin{tabular}{|c|l|}
\hline Escore & $\begin{array}{l}\text { Valores de Referência } \\
\text { A administração municipal tem realizado: }\end{array}$ \\
\hline 1,00 & $\begin{array}{l}\text { Operações de fiscalização, notificação e autuação dos } \\
\text { responsáveis, incluindo aplicação de sanções mais severas como } \\
\text { paralisação das obras ou demolição parcial ou total dos } \\
\text { empreendimentos }\end{array}$ \\
\hline 0,75 & $\begin{array}{l}\text { Operações de fiscalização de obras e empreendimentos em } \\
\text { desacordo com a legislação urbanística municipal, notificação e } \\
\text { autuação dos responsáveis, incluindo aplicação de multas }\end{array}$ \\
\hline 0,50 & $\begin{array}{l}\text { Operações de fiscalização de obras e empreendimentos em } \\
\text { desacordo com a legislação urbanística municipal, porém não tem } \\
\text { autuado ou aplicado qualquer sanção aos responsáveis, limitando- } \\
\text { se a notificação dos mesmos }\end{array}$ \\
\hline 0,00 & $\begin{array}{l}\text { Operações de fiscalização de obras e empreendimentos em } \\
\text { desacordo com a legislação urbanística municipal somente em } \\
\text { caso de denúncias }\end{array}$ \\
\hline $\begin{array}{l}\text { A administração municipal não tem realizado operações de } \\
\text { fiscalização de obras e empreendimentos em desacordo com a } \\
\text { legislação urbanística municipal }\end{array}$ \\
\hline
\end{tabular}

\section{SIMULACÃO AMBICIOSA:}

Variação de Estágio: 1,5 x 0,25 =0,375

Escore a ser atingido: $0,75+0,375=1,00$ (excede o valor máximo)

Valor normalizado: 1,00

Ação consequente: A administração municipal deve realizar aplicação de sanções mais severas a quem não cumpre a Legislação Urbanística vigente, 
incluindo paralisação das obras ou demolição parcial ou total dos empreendimentos.

\section{SIMULACÃO CONSERVADORA:}

Variação de Estágio: $0,25 \times 0,25=0,06$

Escore a ser atingido: $0,75+0,06=0,81$ (por ser qualitativo não se altera 0 escore)

Valor normalizado: 0,75

Ação consequente: A administração municipal deve continuar a fiscalizar obras e empreendimentos em desacordo com a legislação urbanística municipal, notificando e autuando os responsáveis, inclusive com aplicação de multas. 


\begin{tabular}{|l|l|}
\hline DOMÍNIO & Tráfego e Circulação urbana \\
\hline TEMA & Acidentes de trânsito \\
\hline INDICADOR 8.1.1 & Acidentes de trânsito \\
\hline
\end{tabular}

Definição: Número de mortos em acidentes de trânsito ocorridos em vias urbanas no ano de referência, por 100.000 habitantes.

Escore: 0,061 mortos/100.000 habitantes

Normalização: 1,00

Estágios:

\begin{tabular}{|c|l|}
\hline Escore & $\begin{array}{l}\text { Valores de Referência } \\
\text { Número de mortos em acidentes de trânsito ocorridos em vias } \\
\text { urbanas do município no ano de referência por 100.000 habitantes }\end{array}$ \\
\hline 1,00 & Não houve \\
\hline 0,75 & 100 \\
\hline 0,50 & 200 \\
\hline 0,25 & 300 \\
\hline 0,00 & 400 ou mais \\
\hline
\end{tabular}

\section{SIMULACÃO AMBICIOSA:}

Variação de Estágio: 2

Escore a ser atingido: Está no máximo.

Valor normalizado: 1,00

Ação consequente: Manter o número de mortos em acidentes de trânsito em vias urbanas estabilizadas abaixo de 1 a cada 100.000 habitantes/ano.

\section{SIMULAÇ̃̃O CONSERVADORA:}

Variação de Estágio: 1

Escore a ser atingido: Está no máximo.

Valor normalizado: 1,00

Ação consequente: Manter o número de mortos em acidentes de trânsito em vias urbanas estabilizadas abaixo de 1 a cada 100.000 habitantes/ano. 


\begin{tabular}{|l|l|}
\hline DOMÍNIO & Tráfego e Circulação urbana \\
\hline TEMA & Acidentes de trânsito \\
\hline INDICADOR 8.1.2 & Acidentes com pedestres e ciclistas \\
\hline
\end{tabular}

Definição: Porcentagem dos acidentes de trânsito ocorridos no ano de referência em vias urbanas do município envolvendo pedestres e ciclistas.

Escore: 3,33\%

Normalização: 1,00

Estágios:

\begin{tabular}{|c|l|}
\hline Escore & $\begin{array}{l}\text { Valores de Referência } \\
\text { Porcentagem dos acidentes de trânsito ocorridos em vias urbanas } \\
\text { do município no ano de referência envolvendo pedestres e ciclistas }\end{array}$ \\
\hline 1,00 & Até $5 \%$ \\
\hline 0,75 & $10 \%$ \\
\hline 0,50 & $15 \%$ \\
\hline 0,25 & $20 \%$ \\
\hline 0,00 & $25 \%$ ou mais \\
\hline
\end{tabular}

\section{SIMULACÃO AMBICIOSA:}

Variação de Estágio: 2

Escore a ser atingido: Está no máximo

Valor normalizado: 1,00

Ação consequente: Manter o número de acidentes de trânsito ocorridos com pedestres e ciclistas em vias urbanas estabilizado abaixo dos $5 \%$ do total de acidentes.

\section{SIMULAC̄̃O CONSERVADORA:}

Variação de Estágio: 1

Escore a ser atingido: Está no máximo.

Valor normalizado: 1,00

Ação consequente: Manter o número de acidentes de trânsito ocorridos com pedestres e ciclistas em vias urbanas estabilizado abaixo dos $5 \%$ do total de acidentes. 


\begin{tabular}{|l|l|}
\hline DOMÍNIO & Tráfego e Circulação urbana \\
\hline TEMA & Acidentes de trânsito \\
\hline INDICADOR 8.1.3 & Prevenção de acidentes \\
\hline
\end{tabular}

Definição: Porcentagem da extensão de vias locais com dispositivos de moderação de tráfego em relação à extensão total de vias locais do sistema viário urbano.

Observação: A insuficiência de dados impossibilitou a execução do cálculo deste indicador. Deve-se levantar o número de dispositivos de moderação de tráfego implantados em vias locais do município. Nos cenários também não foram calculados para evitar a redistribuição dos pesos entre os indicadores.

\section{Escore: -}

Normalização: -

\section{Estágios:}

\begin{tabular}{|c|l|}
\hline Escore & $\begin{array}{l}\text { Valores de Referência } \\
\text { Porcentagem das vias locais do sistema viário urbano que } \\
\text { apresentam dispositivos de moderação de tráfego }\end{array}$ \\
\hline 1,00 & $100 \%$ \\
\hline 0,75 & $75 \%$ \\
\hline 0,50 & $50 \%$ \\
\hline 0,25 & $25 \%$ \\
\hline 0,00 & $\begin{array}{l}\text { As vias locais do sistema viário urbano não apresentam } \\
\text { dispositivos de moderação de tráfego }\end{array}$ \\
\hline
\end{tabular}

\section{SIMULAC̄̃̃O AMBICIOSA:}

Variação de Estágio: 1,5

Escore a ser atingido: -

Valor normalizado: -

Ação consequente: -

SIMULACÃO CONSERVADORA:

Variação de Estágio: 0,25 
Escore a ser atingido: -

Valor normalizado: -

Ação consequente: 


\begin{tabular}{|l|l|}
\hline DOMÍNIO & Tráfego e Circulação Urbana \\
\hline TEMA & Educação para o trânsito \\
\hline INDICADOR 8.2.1 & Educação para o trânsito \\
\hline
\end{tabular}

Definição: Porcentagem de escolas de nível pré-escolar, fundamental e médio, públicas e particulares, promovendo aulas ou campanhas de educação para o trânsito no ano de referência no município.

Escore: 68,33\%

Normalização: 0,68

Estágios:

\begin{tabular}{|c|l|}
\hline Escore & $\begin{array}{l}\text { Valores de Referência } \\
\text { Porcentagem das escolas públicas ou particulares do município } \\
\text { que implantaram disciplinas ou programas de educação para o } \\
\text { trânsito no ano de referência }\end{array}$ \\
\hline 1,00 & $100 \%$ \\
\hline 0,75 & $75 \%$ \\
\hline 0,50 & $50 \%$ \\
\hline 0,25 & $25 \%$ \\
\hline 0,00 & 0 \\
\hline
\end{tabular}

\section{SIMULACÃO AMBICIOSA:}

Variação de Estágio: 2 × 25\% = 50\%

Escore a ser atingido: $68,33+50=100 \%$ (excede o valor máximo)

Valor normalizado: 1,00

Ação consequente: Implantar disciplinas ou programas de educação para o trânsito nas 120 escolas públicas e particulares do município.

\section{SIMULACÃO CONSERVADORA:}

Variação de Estágio: 1 x 25\% = 25\%

Escore a ser atingido: $68,33+25=93 \%$

Valor normalizado: 0,93

Ação consequente: Implantar disciplinas ou programas de educação para o trânsito em mais 30 escolas públicas e particulares do município, além das 82 onde já existem os programas. 


\begin{tabular}{|l|l|}
\hline DOMÍNIO & Tráfego e Circulação Urbana \\
\hline TEMA & Fluidez e circulação \\
\hline INDICADOR 8.3.1 & Congestionamento \\
\hline
\end{tabular}

Definição: Informações fornecidas pela Prefeitura Municipal de São Carlos, Secretaria Municipal de Transporte, Trânsito e Vias Públicas (2008).

Escore: 0,16 horas/dia

Normalização: 1,00

Estágios:

\begin{tabular}{|c|l|}
\hline Escore & $\begin{array}{l}\text { Valores de Referência } \\
\text { Média diária mensal de horas de congestionamento de tráfego em } \\
\text { vias da rede principal }\end{array}$ \\
\hline 1,00 & Até 1 hora/dia \\
\hline 0,75 & 2 horas/dia \\
\hline 0,50 & 3 horas/dia \\
\hline 0,25 & 4 horas/dia \\
\hline 0,00 & 5 horas/dia ou mais \\
\hline
\end{tabular}

\section{SIMULAÇ̃̃O AMBICIOSA:}

Variação de Estágio: 1,5

Escore a ser atingido: Está no máximo.

Valor normalizado: 1,00

Ação consequente: Manter estabilizada a média mensal de horas de congestionamento de tráfego abaixo de 1 hora/dia nas vias da rede principal.

\section{SIMULAC̄̃̃O CONSERVADORA:}

Variação de Estágio: 0,25

Escore a ser atingido: Está no máximo.

Valor normalizado: 1,00

Ação consequente: Manter estabilizada a média mensal de horas de congestionamento de tráfego abaixo de 1 hora/dia nas vias da rede principal. 


\begin{tabular}{|l|l|}
\hline DOMÍNIO & Tráfego e Circulação Urbana \\
\hline TEMA & Fluidez e Circulação \\
\hline INDICADOR 8.3.2 & Velocidade média do tráfego \\
\hline
\end{tabular}

Definição: Velocidade média de deslocamento em transporte individual motorizado, observada num circuito preestabelecido de vias (rede viária principal), em horário de pico.

Escore: $38,51 \mathrm{~km} / \mathrm{h}$

Normalização: 1,00

Estágios:

\begin{tabular}{|c|l|}
\hline Escore & $\begin{array}{l}\text { Valores de Referência } \\
\text { Velocidade média de tráfego, no pico, em vias da rede principal }\end{array}$ \\
\hline 1,00 & Igual ou superior a $30 \mathrm{~km} / \mathrm{h}$ \\
\hline 0,75 & $25 \mathrm{~km} / \mathrm{h}$ \\
\hline 0,50 & $20 \mathrm{~km} / \mathrm{h}$ \\
\hline 0,25 & $15 \mathrm{~km} / \mathrm{h}$ \\
\hline 0,00 & Até $10 \mathrm{~km} / \mathrm{h}$ \\
\hline
\end{tabular}

\section{SIMULAČ̃̃ AMBICIOSA:}

Variação de Estágio: 1,75

Escore a ser atingido: Está no máximo.

Valor normalizado: 1,00

Ação consequente: Manter a velocidade média de tráfego igual ou superior a $30 \mathrm{~km} / \mathrm{h}$ nos horários de pico em vias da rede principal.

\section{SIMULACÃO CONSERVADORA:}

Variação de Estágio: 0,75

Escore a ser atingido: Está no máximo.

Valor normalizado: 1,00

Ação consequente: Manter a velocidade média de tráfego igual ou superior a $30 \mathrm{~km} / \mathrm{h}$ nos horários de pico em vias da rede principal. 


\begin{tabular}{|l|l|}
\hline DOMÍNIO & Tráfego e Circulação Urbana \\
\hline TEMA & Operação e fiscalização de trânsito \\
\hline INDICADOR 8.4.1 & Violação das leis de trânsito \\
\hline
\end{tabular}

Definição: Porcentagem de condutores habilitados que cometeram infrações em relação ao número de condutores com habilitação no município no ano de referência.

Escore: 0,10\%

Normalização: 1,00

Estágios:

\begin{tabular}{|c|l|}
\hline Escore & $\begin{array}{l}\text { Valores de Referência } \\
\text { Porcentagem dos condutores com habilitação que cometeram } \\
\text { infrações gravíssimas ou atingiram mais de 20 pontos no ano de } \\
\text { referência no município }\end{array}$ \\
\hline 1,00 & Até $2 \%$ \\
\hline 0,75 & $4 \%$ \\
\hline 0,50 & $6 \%$ \\
\hline 0,25 & $8 \%$ \\
\hline 0,00 & $10 \%$ ou mais \\
\hline
\end{tabular}

\section{SIMULACÃO AMBICIOSA:}

Variação de Estágio: 2

Escore a ser atingido: Está no máximo.

Valor normalizado: 1,00

Ação consequente: Manter estabilizada a porcentagem de condutores habilitado que cometeram infração em menos de $2 \%$ do total de condutores com habilitação.

\section{SIMULACÃO CONSERVADORA:}

Variação de Estágio: 1

Escore a ser atingido: Está no máximo.

Valor normalizado: 1,00 
Ação consequente: Manter estabilizada a porcentagem de condutores habilitado que cometeram infração em menos de $2 \%$ do total de condutores com habilitação. 


\begin{tabular}{|l|l|}
\hline DOMÍNIO & Tráfego e Circulação Urbana \\
\hline TEMA & Transporte individual \\
\hline INDICADOR 8.5.1 & Índice de Motorização \\
\hline
\end{tabular}

Definição: Número de automóveis registrados no município por 1.000 habitantes no ano de referência.

Escore: 500 autos/1.000 habitantes ${ }^{15}$

Normalização: 0,00

Estágios:

\begin{tabular}{|c|l|}
\hline Escore & $\begin{array}{l}\text { Valores de Referência } \\
\text { Número de automóveis por } 1.000 \text { habitantes }\end{array}$ \\
\hline 1,00 & Até 250 \\
\hline 0,75 & 300 \\
\hline 0,50 & 350 \\
\hline 0,25 & 400 \\
\hline 0,00 & 450 ou mais \\
\hline
\end{tabular}

\section{SIMULACÃO AMBICIOSA:}

Variação de Estágio: Não há.

Escore a ser atingido: -

Valor normalizado: 0,00

Ação consequente: -

SIMULAÇÃO CONSERVADORA:

Variação de Estágio: Não há.

Escore a ser atingido: -

Valor normalizado: 0,00

Ação consequente: -

15 Dado atualizado em 2010, conforme o censo 2010, cuja população de São Carlos é de 221.936 e o número de carros licenciados está disponível em http://www.saocarlosagora.com.br/brasil/noticia/2011/01/05/14199/venda-de-veiculos-cresce1063-em-2010-frota-de-sao-carlos-ultrapassa-125-mil-veiculos/. Acesso em 12/04/2011. 


\begin{tabular}{|l|l|}
\hline DOMÍNIO & Tráfego e Circulação Urbana \\
\hline TEMA & Transporte individual \\
\hline INDICADOR 8.5.2 & Taxa de ocupação de veículos \\
\hline
\end{tabular}

Definição: Número médio de passageiros em automóveis privados em deslocamentos feitos na área urbana do município, para todos os motivos de viagem.

Escore: 1,56 passageiros/automóvel

Normalização: 0,18

Estágios:

\begin{tabular}{|c|l|}
\hline Escore & $\begin{array}{l}\text { Valores de Referência } \\
\text { Taxa de ocupação média em deslocamentos na área urbana }\end{array}$ \\
\hline 1,00 & 4 passageiros/automóvel \\
\hline 0,66 & 3 passageiros/automóvel \\
\hline 0,33 & 2 passageiros/automóvel \\
\hline 0,00 & 1 passageiro/automóvel \\
\hline
\end{tabular}

\section{SIMULACC̃̃O AMBICIOSA:}

Variação de Estágio: $1 \times 1=1$ passageiro/auto

Escore a ser atingido: $1,56+1=2,56$ passageiro/auto

Valor normalizado: 0,51

Ação consequente: Aumentar a taxa de ocupação média para 2,56 passageiros/automóvel na área urbana.

\section{SIMULACÃO CONSERVADORA:}

Variação de Estágio: $0,1 \times 1=0,1$ passageiro/auto

Escore a ser atingido: $1,56+0,1=1,66$ passageiro/auto

Valor normalizado: 0,22

Ação consequente: Aumentar a taxa de ocupação média para 1,66 passageiros/automóvel na área urbana. 


\begin{tabular}{|l|l|}
\hline DOMÍNIO & Sistemas de Transporte Urbano \\
\hline TEMA & Disponibilidade e qualidade do transporte público \\
\hline INDICADOR 9.1.1 & Extensão da rede de transporte público \\
\hline
\end{tabular}

Definição: Extensão total da rede de transporte público em relação à extensão total do sistema viário urbano.

Escore: $30,18 \%$

Normalização: 0,13

Estágios:

\begin{tabular}{|c|l|}
\hline Escore & $\begin{array}{l}\text { Valores de Referência } \\
\text { Extensão da rede de transporte público em relação a extensão do } \\
\text { sistema viário }\end{array}$ \\
\hline 1,00 & Igual ou superior \\
\hline 0,75 & $80 \%$ \\
\hline 0,50 & $60 \%$ \\
\hline 0,25 & $40 \%$ \\
\hline 0,00 & Até $20 \%$ \\
\hline
\end{tabular}

\section{SIMULACÃO AMBICIOSA:}

Variação de Estágio: 0,5 × 20\% = 10\%

Escore a ser atingido: $30,18+10=40,18 \%$

Valor normalizado: 0,25

Ação consequente: Aumentar a extensão da rede de transporte público em 83,5 km (Para chegar em 335,5 dos 835 km da extensão viária).

\section{SIMULAÇÃO CONSERVADORA:}

Variação de Estágio: Não há.

Escore a ser atingido: -

Valor normalizado: 0,13

Ação consequente: Conservar a extensão da rede de transporte público no mínimo com a atual extensão (252km). 


\begin{tabular}{|l|l|}
\hline DOMÍNIO & Sistemas de Transporte Urbano \\
\hline TEMA & Disponibilidade e qualidade do transporte público \\
\hline INDICADOR 9.1.2 & Frequência de atendimento do transporte público \\
\hline
\end{tabular}

Definição: Frequência média de veículos de transporte coletivo por ônibus em linhas urbanas no município, nos dias úteis e períodos de pico.

Escore: No cálculo inicial do IMUS esse indicador alcançou o Escore de 60 minutos (valor normalizado $=0,00$ ). A Prefeitura Municipal informou que a frequência dos ônibus aumentou em 2009, tendo alterado a frequência de atendimento para 30 minutos (valor normalizado $=0,25$ )

Normalização: 0,25

Estágios:

\begin{tabular}{|c|l|}
\hline Escore & $\begin{array}{l}\text { Valores de Referência } \\
\text { Frequência média de atendimento do serviço de transporte público } \\
\text { por ônibus nos horários de pico }\end{array}$ \\
\hline 1,00 & Até 15 minutos ou 4,00 ônibus/hora \\
\hline 0,75 & 20 minutos ou 3,00 ônibus/hora \\
\hline 0,50 & 25 minutos ou 2,4 ônibus/hora \\
\hline 0,25 & 30 minutos ou 2 ônibus/hora \\
\hline 0,00 & 35 minutos ou mais, ou 1,7 ônibus/hora \\
\hline
\end{tabular}

\section{SIMULACÃO AMBICIOSA:}

Variação de Estágio: $1,75 \times-5=-8,75$ minutos

Escore a ser atingido: $30-8,75=23,75$ minutos

Valor normalizado: 0,56

Ação consequente: $O$ tempo de espera pelos ônibus não pode ultrapassar 23,75 minutos ou seja, aumentar a frequência para 2,52 ônibus/hora.

\section{SIMULACÃO CONSERVADORA:}

Variação de Estágio: $0,75 \times-5=-3,75$ minutos

Escore a ser atingido: $30-3,75=26,25$ minutos

Valor normalizado: 0,72

Ação consequente: $O$ tempo de espera pelos ônibus não pode ultrapassar 26,25 minutos, ou seja, aumentar a frequência para 2,28 ônibus/hora. 


\begin{tabular}{|l|l|}
\hline DOMÍNIO & Sistemas de Transporte Urbano \\
\hline TEMA & Disponibilidade e qualidade do transporte público \\
\hline INDICADOR 9.1.3 & Pontualidade \\
\hline
\end{tabular}

Definição: Porcentagem das viagens em veículos de transporte coletivo por ônibus respeitando a programação horária.

Escore: $93 \%$

Normalização: 0,65

Estágios:

\begin{tabular}{|c|l|}
\hline Escore & $\begin{array}{l}\text { Valores de Referência } \\
\text { Porcentagem das viagens por transporte coletivo por ônibus no } \\
\text { mês analisado que respeitaram os horários programados }\end{array}$ \\
\hline 1,00 & $100 \%$ \\
\hline 0,75 & $95 \%$ \\
\hline 0,50 & $90 \%$ \\
\hline 0,25 & $85 \%$ \\
\hline 0,00 & $80 \%$ ou menos \\
\hline
\end{tabular}

\section{SIMULACÃO AMBICIOSA:}

Variação de Estágio: $1,75 \times 5 \%=8,75 \%$

Escore a ser atingido: $93+8,75=99,25 \%$

Valor normalizado: 0,96

Ação consequente: $99,25 \%$ das viagens por transportes coletivos por ônibus devem respeitar os horários programados.

\section{SIMULACÃO CONSERVADORA:}

Variação de Estágio: $0,75 \times 5 \%=3,75 \%$

Escore a ser atingido: $93+3,75=96,25 \%$

Valor normalizado: 0,84

Ação consequente: $96,75 \%$ das viagens por transportes coletivos por ônibus devem respeitar os horários programados. 


\begin{tabular}{|l|l|}
\hline DOMÍNIO & Sistemas de Transporte Urbano \\
\hline TEMA & Disponibilidade e qualidade do transporte público \\
\hline INDICADOR 9.1.4 & Velocidade média do transporte público \\
\hline
\end{tabular}

Definição: Velocidade média de deslocamento em transporte público por ônibus (velocidade comercial).

Escore: $22,5 \mathrm{~km} / \mathrm{h}$

Normalização: 0,63

Estágios:

\begin{tabular}{|c|l|}
\hline Escore & $\begin{array}{l}\text { Valores de Referência } \\
\text { Velocidade média do serviço de transporte coletivo por ônibus em } \\
\text { horário de pico }\end{array}$ \\
\hline 1,00 & Mais de $25 \mathrm{~km} / \mathrm{h}$ \\
\hline 0,75 & $25 \mathrm{~km} / \mathrm{h}$ \\
\hline 0,50 & $20 \mathrm{~km} / \mathrm{h}$ \\
\hline 0,25 & $15 \mathrm{~km} / \mathrm{h}$ \\
\hline 0,00 & Igual ou inferior a $10 \mathrm{~km} / \mathrm{h}$ \\
\hline
\end{tabular}

\section{SIMULACÃO AMBICIOSA:}

Variação de Estágio: $1,5 \times 5=7,5 \mathrm{~km} / \mathrm{h}$

Escore a ser atingido: $22,5+7,5=30 \mathrm{~km} / \mathrm{h}$

Valor normalizado: 1,00

Ação consequente: A velocidade média do serviço de transporte coletivo por ônibus deve ter um aumento de mais que $2,5 \mathrm{~km} / \mathrm{h}$ para que seja maior que 25 $\mathrm{km} / \mathrm{h}$.

\section{SIMULAC̄̃̃O CONSERVADORA:}

Variação de Estágio: $0,5 \times 5=2,5 \mathrm{~km} / \mathrm{h}$

Escore a ser atingido: $22,5+2,5=25 \mathrm{~km} / \mathrm{h}$

Valor normalizado: 0,75

Ação consequente: A velocidade média do serviço de transporte coletivo por ônibus deve ter um aumento de mais que $2,5 \mathrm{~km} / \mathrm{h}$ para que seja de $25 \mathrm{~km} / \mathrm{h}$. 


\begin{tabular}{|l|l|}
\hline DOMÍNIO & Sistemas de Transporte Urbano \\
\hline TEMA & Disponibilidade e qualidade do transporte público \\
\hline INDICADOR 9.1.5 & Idade média da frota de transporte público \\
\hline
\end{tabular}

Definição: Idade média da frota de ônibus e microônibus urbanos no ano de referência no município.

Escore: 6,09 anos

Normalização: 0,81

Estágios:

\begin{tabular}{|c|l|}
\hline Escore & $\begin{array}{l}\text { Valores de Referência } \\
\text { Idade média da frota de ônibus e micro-ônibus urbanos }\end{array}$ \\
\hline 1,00 & Até 5 anos \\
\hline 0,66 & 7 anos \\
\hline 0,33 & 9 anos \\
\hline 0,00 & 11 anos ou mais \\
\hline
\end{tabular}

\section{SIMULACC̃O AMBICIOSA:}

Variação de Estágio: $1,75 \times-2=-3,5$ anos

Escore a ser atingido: $6,09-3,5=5$ anos

Valor normalizado: 1,00

Ação consequente: A idade média da frota tem que ser igual ou menor que 5 anos.

\section{SIMULAC̄̃̃O CONSERVADORA:}

Variação de Estágio: $0,75 \times-2=-1,5$ ano

Escore a ser atingido: $6,09-1,5=5,5$ anos

Valor normalizado: 0,91

Ação consequente: A idade média da frota tem que ser igual a 5,5 anos. 


\begin{tabular}{|l|l|}
\hline DOMÍNIO & Sistemas de Transporte Urbano \\
\hline TEMA & Disponibilidade e qualidade do transporte público \\
\hline INDICADOR 9.1.6 & Índice de passageiros por quilômetro \\
\hline
\end{tabular}

Definição: Razão entre o número total de passageiros transportados e a quilometragem percorrida pela frota de transporte púbico do município.

Escore: 2,00

Normalização: 0,00

Estágios:

\begin{tabular}{|c|l|}
\hline Escore & $\begin{array}{l}\text { Valores de Referência } \\
\text { IPK do serviço de transporte público por ônibus no ano de } \\
\text { referência (ou mês observado) }\end{array}$ \\
\hline 1,00 & Igual ou superior a 4,5 até o limite de 5 passageiros $/ \mathrm{km}$ \\
\hline 0,75 & 4 passageiros $/ \mathrm{km}$ \\
\hline 0,50 & 3,5 passageiros $/ \mathrm{km}$ \\
\hline 0,25 & 3 passageiros $/ \mathrm{km}$ \\
\hline 0,00 & Até 2,5 ou superior a 5 passageiros $/ \mathrm{km}$ \\
\hline
\end{tabular}

\section{SIMULACÃO AMBICIOSA:}

Variação de Estágio: $1,5 \times 0,5=0,75$ passageiros $/ \mathrm{km}$

Escore a ser atingido: $2+0,75=2,75$ passageiros $/ \mathrm{km}$

Valor normalizado: 0,13

Ação consequente: O IPK deve ser aumentado em 0,75 passageiros $/ \mathrm{km}$ para que seja de 2,75 passageiros $/ \mathrm{km}^{16}$.

\section{SIMULACÃO CONSERVADORA:}

Variação de Estágio: $0,25 \times 0,5=0,125$ passageiros $/ \mathrm{km}$

Escore a ser atingido: $2+0,125=2,13$ passageiros $/ \mathrm{km}$

Valor normalizado: 0,00

Ação consequente: O IPK deve ser aumentado em 0,13 passageiros $/ \mathrm{km}$ para que seja de 2,13 passageiros $/ \mathrm{km}$.

\footnotetext{
${ }^{16}$ Isso significa aumentar um determinado número de passageiros, dado que não foi possível obter na pesquisa.
} 


\begin{tabular}{|l|l|}
\hline DOMÍNIO & Sistemas de Transporte Urbano \\
\hline TEMA & Disponibilidade e qualidade do transporte público \\
\hline INDICADOR 9.1.7 & Passageiros transportados anualmente \\
\hline
\end{tabular}

Definição: Variação em termos percentuais do número de passageiros transportados pelos serviços de transporte público urbano no município para um período de 25 anos.

Escore: Decréscimo inferior a 25\%.

Normalização: 0,25

\section{Estágios:}

\begin{tabular}{|c|l|}
\hline Escore & $\begin{array}{l}\text { Valores de Referência } \\
\text { Foi observado para o número de passageiros transportados em } \\
\text { dois anos distintos no município: }\end{array}$ \\
\hline 1,00 & Crescimento superior a 25\% \\
\hline 0,75 & Crescimento inferior a 25\% \\
\hline 0,50 & O número de passageiros transportados permaneceu constante \\
\hline 0,25 & Decréscimo inferior a 25\% \\
\hline 0,00 & Decréscimo superior a 25\% \\
\hline
\end{tabular}

\section{SIMULACÃO AMBICIOSA:}

Variação de Estágio: $1,5 \times 0,25=0,375$

Escore a ser atingido: $0,25+0,375=0,625$ (pro ser qualitativo, aproxima-se de 0,75 )

Valor normalizado: 0,75

Ação consequente: Promover um crescimento de até $25 \%$ a cada dois anos no número de passageiros do transporte público urbano.

\section{SIMULACÃO CONSERVADORA:}

Variação de Estágio: $0,5 \times 0,25=0,125$

Escore a ser atingido: $0,25+0,125=0,375$ (por ser qualitativo, aproxima-se de 0,50)

Valor normalizado: 0,50

Ação consequente: $O$ número de passageiros transportados no transporte público urbano deve ser mantido estável ou permanecer constante. 


\begin{tabular}{|l|l|}
\hline DOMÍNIO & Sistemas de Transporte Urbano \\
\hline TEMA & Disponibilidade e qualidade do transporte público \\
\hline INDICADOR 9.1.8 & $\begin{array}{l}\text { Satisfação do usuário com o serviço de transporte } \\
\text { público }\end{array}$ \\
\hline
\end{tabular}

Definição: Porcentagem da população satisfeita com o serviço de transporte público urbano e metropolitano em todas as suas modalidades.

Escore: $18 \%$

Normalização: 0,18

Estágios:

\begin{tabular}{|c|l|}
\hline Escore & $\begin{array}{l}\text { Valores de Referência } \\
\text { Porcentagem da população (ou dos entrevistados) que está } \\
\text { totalmente satisfeita (ou percebe o serviço como excelente) com o } \\
\text { sistema de transporte público urbano e metropolitano }\end{array}$ \\
\hline 1,00 & $100 \%$ \\
\hline 0,75 & $75 \%$ \\
\hline 0,50 & $50 \%$ \\
\hline 0,25 & $25 \%$ \\
\hline 0,00 & 0 \\
\hline
\end{tabular}

SIMULACÃO AMBICIOSA:

Variação de Estágio: $1,5 \times 25 \%=37,5 \%$

Escore a ser atingido: $18+37,5=55,50 \%$

Valor normalizado: 0,56

Ação consequente: Possuir pelo menos $55,5 \%$ da população satisfeita com 0 sistema de transporte público urbano.

\section{SIMULAC̄̃̃O CONSERVADORA:}

Variação de Estágio: $0,25 \times 25 \%=6,25 \%$

Escore a ser atingido: $18+6,25=24,25 \%$

Valor normalizado: 0,24

Ação consequente: Possuir pelo menos $24,25 \%$ da população satisfeita com o sistema de transporte público urbano. 


\begin{tabular}{|l|l|}
\hline DOMÍNIO & Sistemas de Transporte Urbano \\
\hline TEMA & Diversificação modal \\
\hline INDICADOR 9.2.1 & Diversidade de modos de transporte \\
\hline
\end{tabular}

Definição: Número de modos de transporte disponíveis na cidade.

Escore: 4

Normalização: 0,75

Estágios:

\begin{tabular}{|c|l|}
\hline Escore & $\begin{array}{l}\text { Valores de Referência } \\
\text { Número de modos de transporte (público, semipúblico e privado) } \\
\text { que a cidade dispõe }\end{array}$ \\
\hline 1,00 & 5 ou mais \\
\hline 0,75 & 4 \\
\hline 0,50 & 3 \\
\hline 0,25 & 2 \\
\hline 0,00 & 1 (modo privado, automóvel) \\
\hline
\end{tabular}

SIMULACÃO AMBICIOSA:

Variação de Estágio: $1 \times 1=1$ modo

Escore a ser atingido: $4+1=5$ modos

Valor normalizado: 1,00

Ação consequente: Disponibilizar mais um modo de transporte, seja ele público, semipúblico ou privado.

\section{SIMULACÃO CONSERVADORA:}

Variação de Estágio: $0,1 \times 1=0.1$ (Porém, por serem números inteiros, não altera)

Escore a ser atingido: -

Valor normalizado: 4

Ação consequente: Manter os quatro modos de transportes que a cidade dispõe. 


\begin{tabular}{|l|l|}
\hline DOMÍNIO & Sistemas de Transporte Urbano \\
\hline TEMA & Diversificação modal \\
\hline INDICADOR 9.2.2 & Transporte coletivo $x$ transporte individual \\
\hline
\end{tabular}

Definição: Razão entre o número diário de viagens na área urbana ou metropolitana feitas por modos coletivos de transporte e o número diário de viagens feitas por modos individuais de transporte motorizados.

Escore: 0,6

Normalização: 0,00

Estágios:

\begin{tabular}{|c|l|}
\hline Escore & $\begin{array}{l}\text { Valores de Referência } \\
\text { Razão entre o número diário de viagens na área urbana feitas por } \\
\text { modos coletivos e o número diário de viagens feitas por modos } \\
\text { individuais de transporte motorizados }\end{array}$ \\
\hline 1,00 & Igual ou superior a 5 \\
\hline 0,75 & 4 \\
\hline 0,50 & 3 \\
\hline 0,25 & 2 \\
\hline 0,00 & Igual ou inferior a 1 \\
\hline
\end{tabular}

SIMULACÃO AMBICIOSA:

Variação de Estágio: $0,5 \times 1=0,5$

Escore a ser atingido: $0,6+0,5=1,1$

Valor normalizado: 0,00

Ação consequente: Igualar o número de viagens diárias na área urbana feitas por modo coletivo com o de viagens feitas por modos individuais motorizados.

\section{SIMULAC̄̃̃O CONSERVADORA:}

Variação de Estágio: Não há.

Escore a ser atingido: -

Valor normalizado: -

Ação consequente: - 


\begin{tabular}{|l|l|}
\hline DOMÍNIO & Sistemas de Transporte Urbano \\
\hline TEMA & Diversificação modal \\
\hline INDICADOR 9.2.3 & Modos não motorizados x modos motorizados \\
\hline
\end{tabular}

Definição: Razão entre o número diário de viagens na área urbana ou metropolitana feitas por modos não motorizados de transporte e número diário de viagens feitas por modos motorizados de transporte.

Escore: 0,43

Normalização: 0,00

Estágios:

\begin{tabular}{|c|l|}
\hline Escore & $\begin{array}{l}\text { Valores de Referência } \\
\text { Razão entre o número diário de viagens na área urbana feitas por } \\
\text { modos não motorizados e o número diário de viagens feitas por } \\
\text { modos motorizados de transporte }\end{array}$ \\
\hline 1,00 & Igual ou superior a 2 \\
\hline 0,75 & 1,75 \\
\hline 0,50 & 1,50 \\
\hline 0,25 & 1,25 \\
\hline 0,00 & Igual ou inferior 1 \\
\hline
\end{tabular}

\section{SIMULACÃO AMBICIOSA:}

Variação de Estágio: $0,5 \times 0,25=0,125$

Escore a ser atingido: $0,43+0,125=0,555$ (majorado para 1 por ser uma simulação ambiciosa, porém ainda não há variação)

Valor normalizado: 0,00

Ação consequente: Igualar o número de viagens diárias na área urbana feitas por modos não motorizados com o de viagens feitas por modos motorizados.

\section{SIMULACÃO CONSERVADORA:}

Variação de Estágio: Não há.

Escore a ser atingido: -

Valor normalizado: 0,00

Ação consequente: - 


\begin{tabular}{|l|l|}
\hline DOMÍNIO & Sistemas de Transporte Urbano \\
\hline TEMA & Regulação e fiscalização do transporte público \\
\hline INDICADOR 9.3.1 & Contratos e licitações \\
\hline
\end{tabular}

Definição: Porcentagem dos contratos de operação de serviços de transporte público que se encontram regularizados.

Escore: $100 \%$

Normalização: 1,00

Estágios:

\begin{tabular}{|c|l|}
\hline Escore & $\begin{array}{l}\text { Valores de Referência } \\
\text { Porcentagem dos contratos de prestação de serviços de } \\
\text { transportes que se encontram regularizados }\end{array}$ \\
\hline 1,00 & $100 \%$ \\
\hline 0,75 & $75 \%$ \\
\hline 0,50 & $50 \%$ \\
\hline 0,25 & $25 \%$ \\
\hline 0,00 & 0 \\
\hline
\end{tabular}

SIMULACÃO AMBICIOSA:

Variação de Estágio: 2

Escore a ser atingido: Está no máximo.

Valor normalizado: 1,00

Ação consequente: Manter todos os contratos de prestação de serviços de transportes regularizados.

\section{SIMULACÃO CONSERVADORA:}

\section{Variação de Estágio: 1}

Escore a ser atingido: Está no máximo.

Valor normalizado: 1,00

Ação consequente: Manter todos os contratos de prestação de serviços de transportes regularizados. 


\begin{tabular}{|l|l|}
\hline DOMÍNIO & Sistemas de Transporte Urbano \\
\hline TEMA & Regulação e fiscalização do transporte público \\
\hline INDICADOR 9.3.2 & Transporte clandestino \\
\hline
\end{tabular}

Definição: Participação do transporte clandestino ou irregular nos deslocamentos urbanos.

Escore: Inexpressiva ou inexistente, tendo sido combatidos, regulamentados ou incorporados ao sistema formal.

Normalização: 1,00

Estágios:

\begin{tabular}{|c|c|}
\hline Escore & $\begin{array}{l}\text { Valores de Referência } \\
\text { A participação do transporte clandestino no sistema de transporte } \\
\text { público urbano é: }\end{array}$ \\
\hline 1,00 & 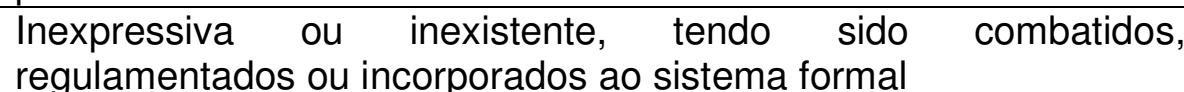 \\
\hline 0,75 & Pequena, predominando os serviços de vans e peruas irregulares \\
\hline 0,50 & $\begin{array}{l}\text { Pequena, predominando os serviços de vans e peruas irregulares } \\
\text { e mototáxi }\end{array}$ \\
\hline 0,25 & $\begin{array}{l}\text { Expressiva, predominando os serviços de vans e peruas } \\
\text { irregulares, mototáxi e táxi-lotação }\end{array}$ \\
\hline 0,00 & $\begin{array}{l}\text { Expressiva, existindo serviços de natureza diversa como vans e } \\
\text { peruas irregulares, mototáxi, táxi-lotação, ônibus piratas e } \\
\text { automóveis }\end{array}$ \\
\hline
\end{tabular}

\section{SIMULACÃO AMBICIOSA:}

Variação de Estágio: 2

Escore a ser atingido: Está no máximo.

Valor normalizado: 1,00

Ação consequente: Manter a participação do transporte clandestino inexpressiva ou inexistente no transporte público urbano e ainda combatê-lo, regulamentá-lo ou incorporá-lo ao sistema formal.

\section{SIMULAÇÃO CONSERVADORA:}

Variação de Estágio: 1

Escore a ser atingido: Está no máximo.

Valor normalizado: 1,00 
Ação consequente: Manter a participação do transporte clandestino inexpressiva ou inexistente no transporte público urbano e ainda combatê-lo, regulamentá-lo ou incorporá-lo ao sistema formal. 


\begin{tabular}{|l|l|}
\hline DOMÍNIO & Sistemas de Transporte Urbano \\
\hline TEMA & Integração do transporte público \\
\hline INDICADOR 9.4.1 & Terminais intermodais \\
\hline
\end{tabular}

Definição: Porcentagem dos terminais de transporte urbano/metropolitano de passageiros que permitem a integração física de dois ou mais modos de transporte público.

Escore: $0 \%$

Normalização: 0,00

Estágios:

\begin{tabular}{|c|l|}
\hline Escore & $\begin{array}{l}\text { Valores de Referência } \\
\text { Porcentagem dos terminais de transporte público urbano que } \\
\text { permitem integração entre dois os mais modos de transporte } \\
\text { público }\end{array}$ \\
\hline 1,00 & Mais de 75\% \\
\hline 0,75 & $75 \%$ \\
\hline 0,50 & $50 \%$ \\
\hline 0,25 & $25 \%$ \\
\hline 0,00 & 0 \\
\hline
\end{tabular}

\section{SIMULACÃO AMBICIOSA:}

Variação de Estágio: $1,5 \times 25 \%=37,5 \%$

Escore a ser atingido: $0,00+37,5=37,5 \%$

Valor normalizado: 0,38

Ação consequente: Dotar um dos terminais de transporte público urbano com integração entre dois ou mais meios de transporte público e preparar os outros para futura implementação.

\section{SIMULAÇÃO CONSERVADORA:}

Variação de Estágio: $0,25 \times 25 \%=6,25 \%$

Escore a ser atingido: $0,00+6,25=6,25 \%$ (como São Carlos possui apenas 3 terminais, este valor é adotado como zero).

Valor normalizado: 0,00

Ação consequente: - 


\begin{tabular}{|l|l|}
\hline DOMÍNIO & Sistemas de Transporte Urbano \\
\hline TEMA & Integração do transporte público \\
\hline INDICADOR 9.4.2 & Integração do transporte público \\
\hline
\end{tabular}

Definição: Grau de integração do sistema de transporte público urbano e metropolitano.

Escore: O sistema de transporte público é totalmente integrado com o uso de bilhete eletrônico para integração intermodal e de sistemas adjacentes (intermunicipais ou metropolitanos).

Normalização: 1,00

Estágios:

\begin{tabular}{|c|l|}
\hline Escore & Valores de Referência \\
\hline 1,00 & $\begin{array}{l}\text { O sistema de transporte público é totalmente integrado com o uso } \\
\text { de bilhete eletrônico para integração intermodal e de sistemas } \\
\text { adjacentes (intermunicipais ou metropolitanos) }\end{array}$ \\
\hline 0,75 & $\begin{array}{l}\text { E praticada a integração física e tarifária temporal em terminais } \\
\text { fechados e em qualquer ponto do sistema de transporte público } \\
\text { urbano, para o mesmo modo de transporte e entre diferentes } \\
\text { modos (transferências intramodais e intermodais) }\end{array}$ \\
\hline 0,50 & $\begin{array}{l}\text { É praticada a integração física e tarifária temporal somente em } \\
\text { terminais fechados do sistema de transporte público urbano, para } \\
\text { o mesmo modo de transporte (transferências intramodais) }\end{array}$ \\
\hline 0,25 & $\begin{array}{l}\text { É praticada somente a integração física em terminais fechados do } \\
\text { sistema de transporte público urbano, para o mesmo modo de } \\
\text { transporte (transferências intramodais) }\end{array}$ \\
\hline 0,00 & $\begin{array}{l}\text { Não é praticada nenhuma forma de integração física ou tarifária no } \\
\text { sistema de transporte público urbano }\end{array}$ \\
\hline
\end{tabular}

\section{SIMULACÃO AMBICIOSA:}

Variação de Estágio: 2

Escore a ser atingido: Está no máximo.

Valor normalizado: 1,00

Ação consequente: Manter a integração do transporte público com o uso de bilhete eletrônico inclusive para integração intermodal.

\section{SIMULACÃO CONSERVADORA:}

Variação de Estágio: 1 
Escore a ser atingido: Está no máximo.

Valor normalizado: 1,00

Ação consequente: Manter a integração do transporte público com o uso de bilhete eletrônico inclusive para integração intermodal. 


\begin{tabular}{|l|l|}
\hline DOMÍNIO & Sistemas de Transporte Urbano \\
\hline TEMA & Política Tarifária \\
\hline INDICADOR 9.5.1 & Descontos e gratuidades \\
\hline
\end{tabular}

Definição: Porcentagem dos usuários do sistema de transporte público que usufruem de descontos ou gratuidade do valor da tarifa.

Escore: $56 \%$

Normalização: 0,00

Estágios:

\begin{tabular}{|c|l|}
\hline Escore & $\begin{array}{l}\text { Valores de Referência } \\
\text { Porcentagem dos embarques (ou usuários) do sistema de } \\
\text { transporte público no período de análise que tiveram desconto ou } \\
\text { gratuidade da tarifa }\end{array}$ \\
\hline 1,00 & Até $10 \%$ \\
\hline 0,75 & $20 \%$ \\
\hline 0,50 & $30 \%$ \\
\hline 0,25 & $40 \%$ \\
\hline 0,00 & $50 \%$ ou mais \\
\hline
\end{tabular}

\section{SIMULACC̃O AMBICIOSA:}

Variação de Estágio: $1,5 x-10 \%=-15 \%$

Escore a ser atingido: $56-15=41 \%$

Valor normalizado: 0,23

Ação consequente: Diminuir em 15\% o número de usuários do sistema de transporte público que possui descontos ou gratuidade na tarifa.

\section{SIMULACÃO CONSERVADORA:}

Variação de Estágio: $0,5 \times-10=-5 \%$

Escore a ser atingido: $56-5=51 \%$

Valor normalizado: 0,00

Ação consequente: Diminuir em 5\% o número de usuários do sistema de transporte público que possui descontos ou gratuidade na tarifa. 


\begin{tabular}{|l|l|}
\hline DOMÍNIO & Sistemas de Transportes Urbanos \\
\hline TEMA & Política tarifária \\
\hline INDICADOR 9.5.2 & Tarifas de transporte \\
\hline
\end{tabular}

Definição: Variação percentual dos valores de tarifa de transporte público urbano para um período de análise, comparada a índices inflacionários para 0 mesmo período.

Escore: As tarifas de transporte público apresentaram, em relação ao índice inflacionário selecionado, aumento superior ao índice.

Normalização: 0,00

\section{Estágios:}

\begin{tabular}{|c|l|}
\hline Escore & $\begin{array}{l}\text { Valores de Referência } \\
\text { As tarifas de transporte público apresentaram, em relação ao } \\
\text { índice inflacionário selecionado: }\end{array}$ \\
\hline 1,00 & Não houve aumento da tarifa \\
\hline 0,66 & Aumento inferior ao índice \\
\hline 0,33 & Aumento equivalente ao índice \\
\hline 0,00 & Aumento superior ao índice \\
\hline
\end{tabular}

\section{SIMULACÃO AMBICIOSA:}

Variação de Estágio: $1,5 \times 0,33=0,495$

Escore a ser atingido: $0,00+0,495=0,495$ (por ser qualitativo aproximou-se de 0,33)

Valor normalizado: 0,33

Ação consequente: A tarifa do transporte público pode apresentar aumento que seja equivalente ao índice inflacionário do período.

\section{SIMULACÃO CONSERVADORA:}

Variação de Estágio: $0,5 \times 0,33=0,165$

Escore a ser atingido: $0,00+0,165=0,16$ (por ser quantitativo aproximou-se de 0,33)

Valor normalizado: 0,33

Ação consequente: A tarifa do transporte público pode apresentar aumento que seja equivalente ao índice inflacionário do período. 


\begin{tabular}{|l|l|}
\hline DOMÍNIO & Sistemas de Transporte Urbano \\
\hline TEMA & Política tarifária \\
\hline INDICADOR 9.5.3 & Subsídios públicos \\
\hline
\end{tabular}

Definição: Subsídios públicos oferecidos aos sistemas de transporte urbano/metropolitano.

Escore: Há subsídios públicos para a totalidade do sistema de transporte público urbano e metropolitano, visando a redução da tarifa de transporte.

Normalização: 1,00

Estágios:

\begin{tabular}{|c|l|}
\hline Escore & $\begin{array}{l}\text { Valores de Referência } \\
\text { Há subsídios: }\end{array}$ \\
\hline 1,00 & $\begin{array}{l}\text { Públicos para a totalidade do sistema de transporte público } \\
\text { urbano e metropolitano, visando a redução da tarifa de transporte }\end{array}$ \\
\hline 0,75 & $\begin{array}{l}\text { Públicos para serviços deficitários (alta capacidade ou metro- } \\
\text { ferroviários) e serviços especiais de transporte (pessoas com } \\
\text { necessidades especiais, etc) }\end{array}$ \\
\hline 0,50 & $\begin{array}{l}\text { Público somente para serviços deficitários (alta capacidade ou } \\
\text { metro-ferroviários) }\end{array}$ \\
\hline 0,25 & $\begin{array}{l}\text { Há somente mecanismos de subsídio interno para compensação } \\
\text { em sistema de transporte urbano com tarifa única }\end{array}$ \\
\hline 0,00 & $\begin{array}{l}\text { Não há qualquer subsídio público ou mecanismos de de } \\
\text { compensação para os sistemas de transporte } \\
\text { urbano/metropolitano }\end{array}$ \\
\hline
\end{tabular}

\section{SIMULACÃO AMBICIOSA:}

Variação de Estágio: 1,75

Escore a ser atingido: Está no máximo.

Valor normalizado: 1,00

Ação consequente: Manter os subsídios públicos para a totalidade do sistema de transporte público visando a redução da tarifa de transporte.

\section{SIMULACÃ̃O CONSERVADORA:}

Variação de Estágio: 0,75

Escore a ser atingido: Está no máximo.

Valor normalizado: 1,00

Ação consequente: Manter os subsídios públicos para a totalidade do sistema de transporte público visando a redução da tarifa de transporte. 